
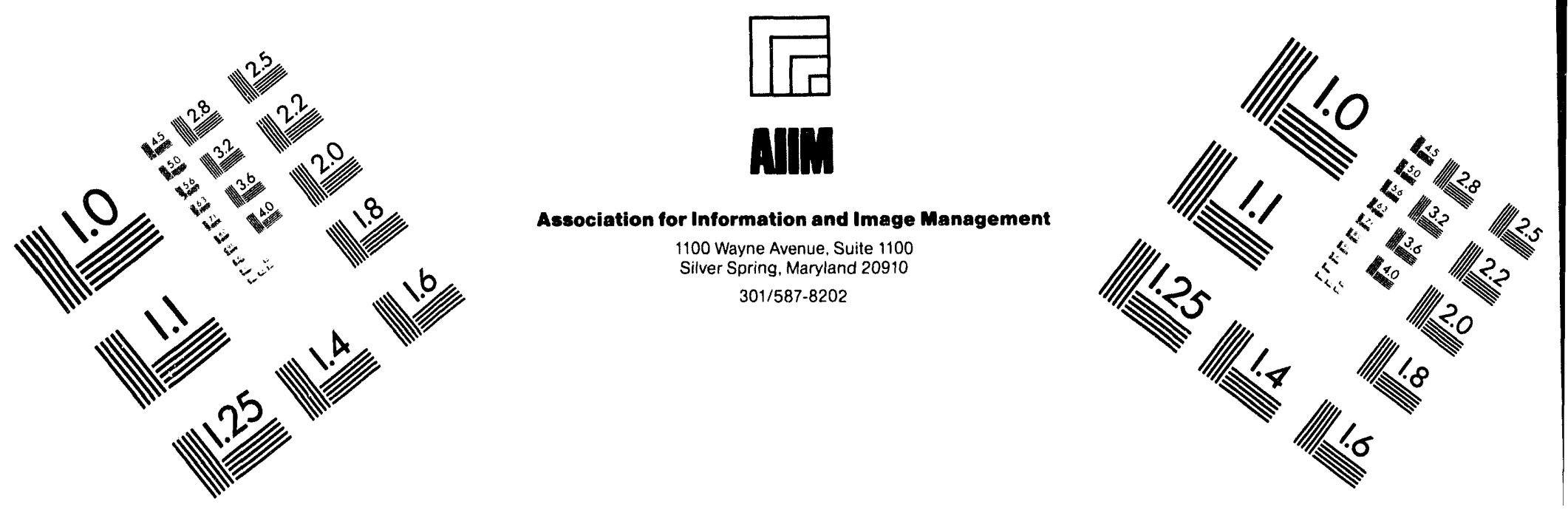

\title{
Centimeter
}

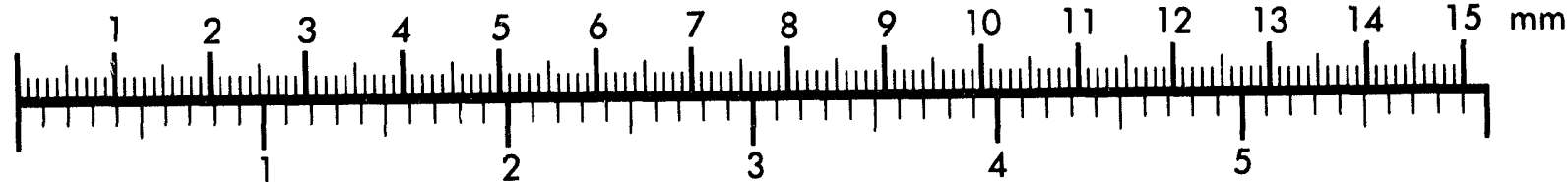
Inches
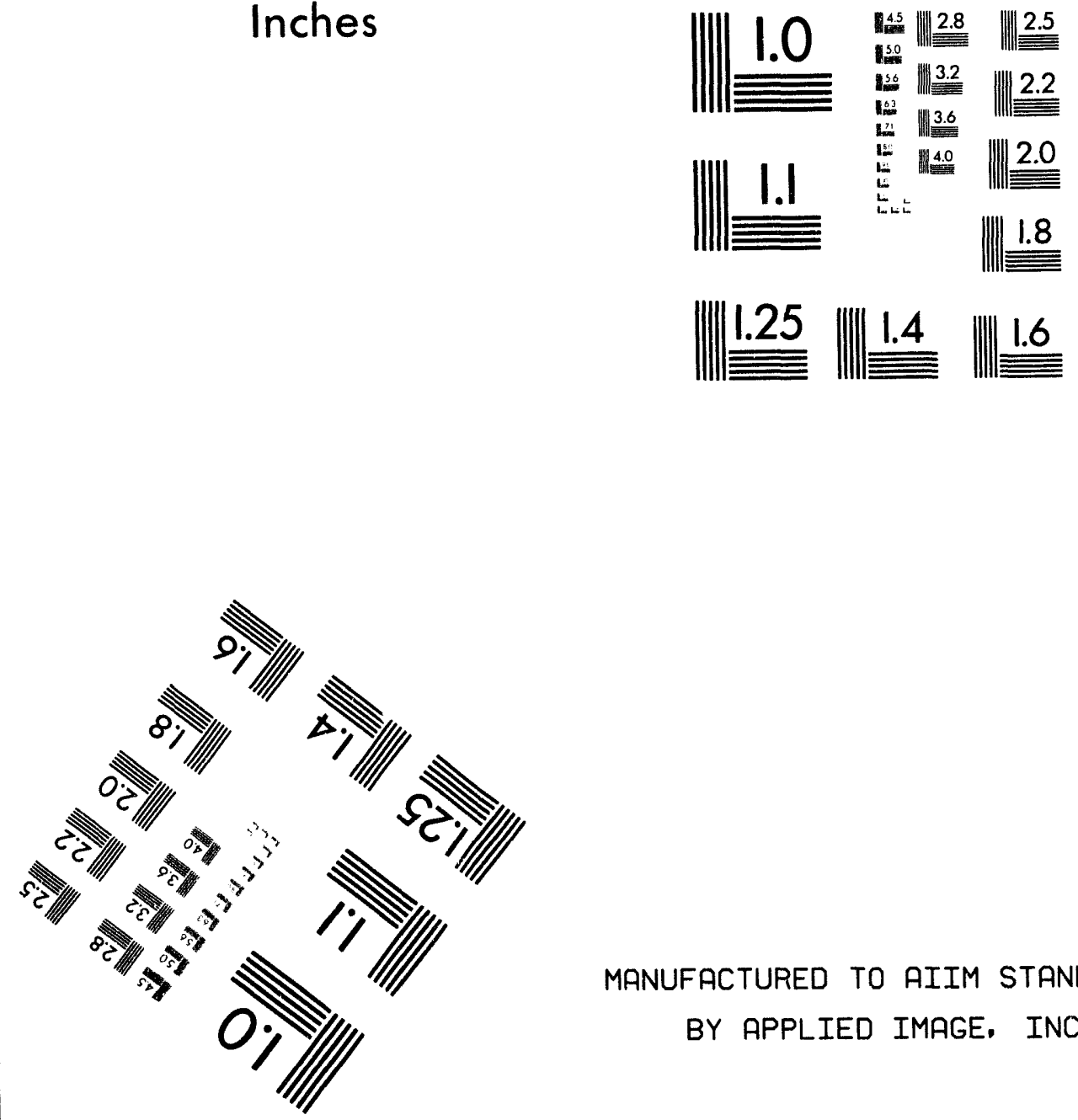

MANUFACTURED TO AIIM STANDARDS

BY APPLIED IMAGE, INC.

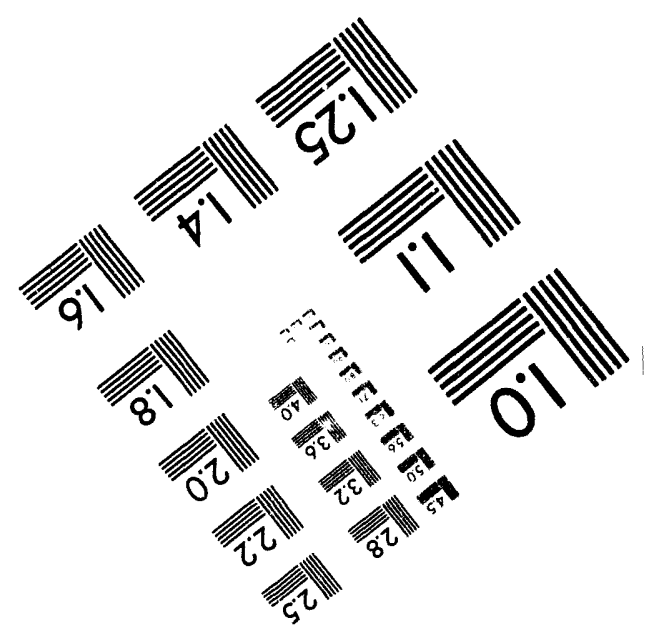



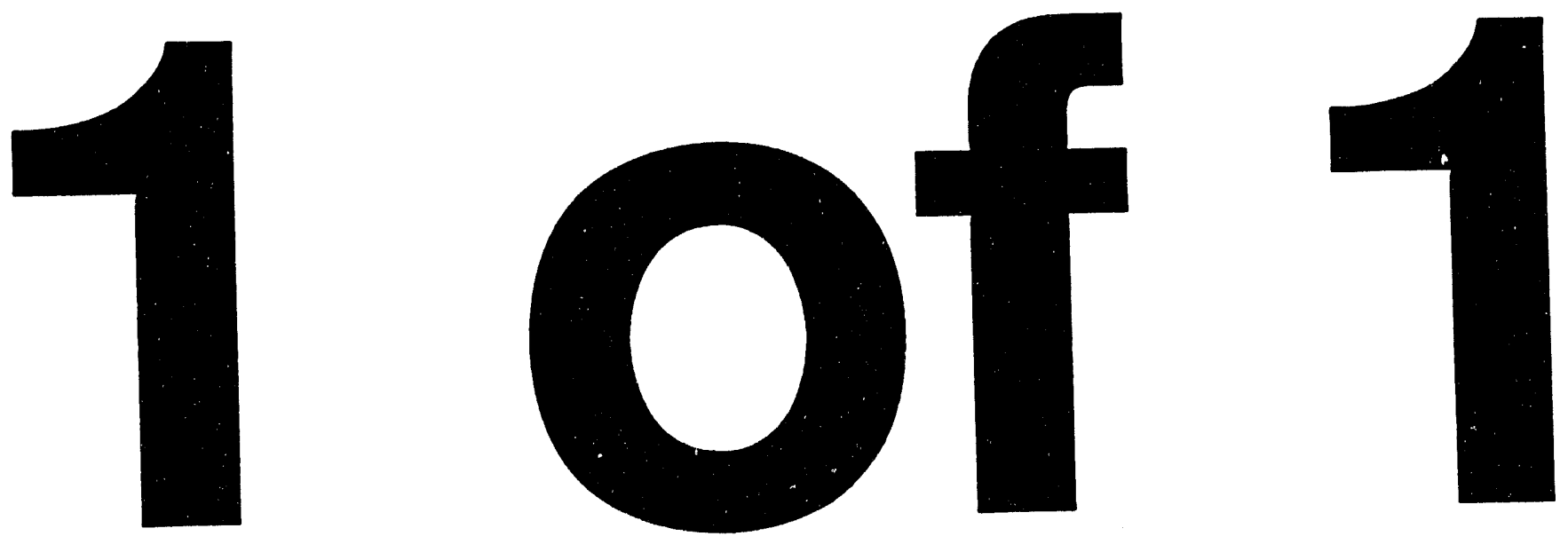
Federal Advisory Committee To Develop On-Site Innovative Technologies

\section{MILITARY MUNITIONS WASTE WORKING GROUP REPORT}

\section{November 30, 1993}
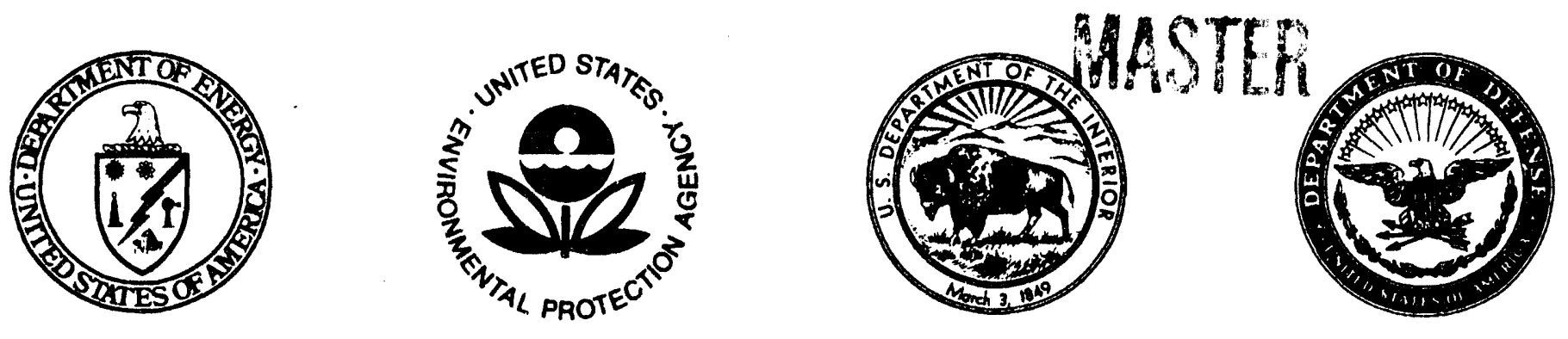

So 


\section{Table of Contents}

EXECUTIVE SUMMARY vii

1.0 INTRODUCTION 1

2.0 MIIIARY MUNITIONS WASTE WORKING GROUP CHARTER .... 4

3.0 DESCRIPTION OF PRIORITY WASTE STREAM PROBLEMS ...... 4

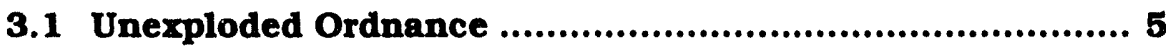

3.1.1 Stockpiled Material in Magazine ............................................ 5

3.1.2 Disposed (known areas of disposal, e.g., disposal pits) .................5

3.1.3 Discharged (unknown areas of disposal, e.g., ranges) .................. 5

3.2 Contaminated Media ............................................ 5

3.3 Chemical Sureties/Weapons ...................................... 6

3.4 Biological Weapons (waste handling only) ..................... 6

3.5 Munitions Production ............................................. 6

3.5.1 Environmental Restoration at a site .....................................6 6

3.5.2 Waste Management with Discrete Stream ................................6

3.6 Remediation of Depleted Uranium ............................ 6

3.7 Rocket Motor and Fuel Disposal ................................ 7

4.0 SHORTCOMINGS OF EXISTING APPROACHES, PROCESSES, AND TECHNOLOGIES .................................................. 7

4.1 Approaches ............................................................ 7

4.1.1 Stakeholder Participation .......................................... 7

4.1.2 Information Sharing ............................................... 8

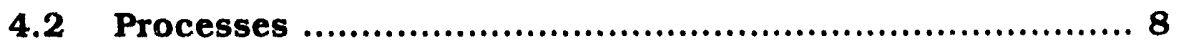

4.2.1 Decisionmakers Disincentive ........................................ 8

4.2.2 Inadequate and Inappropriate Regulations .........................8 
4.3 Technologies ..................................................... 9

4.3.1 Unexploded Ordnance …................................................................ 9

4.4 Contaminated Media ........................................... 13

5.0 INNOVATIVE APPROACHES, PROCESSES, AND

TECHNOLOGIES ..................................................... 14

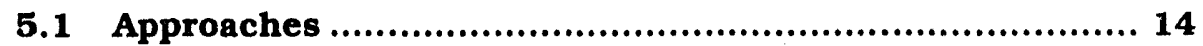

5.1.1 Stakeholder Participation ............................................... 14

5.1.2 Information Sharing ................................................. 14

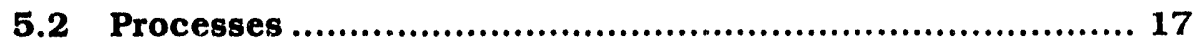

5.2.1 Decisionmaker Disincentives ........................................ 17

5.2.2 Inadequate or Inappropriate Regulations ............................ 17

5.3 Technologies..................................................... 18

5.3.1 Unexploded Ordnance ................................................. 18

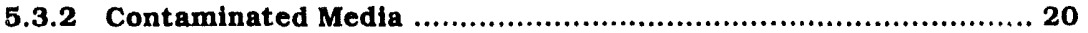

6.0 WORK FORCE PLANNING, TRAINING, AND EDUCATION ISSUES RELATIVE TO TECHNOLOGY DEPLOYMENT AND CLEANUP .... 21

7.0 CRITERIA USED TO IDENTIFY AND SCREEN POTENTLAL DEMONSTRATION PROJECTS

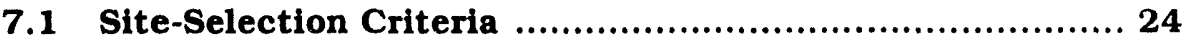

7.2 Technology Selection Criteria ................................ 26

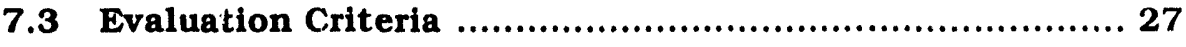

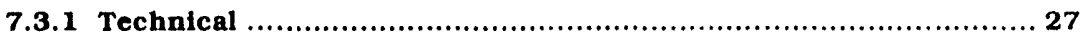

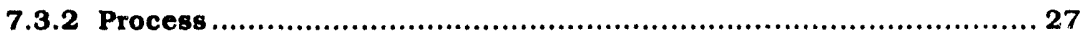

7.4 Contractor Selection Criteria ................................. 27

8.0 LIST OF POTENTIAL CANDIDATE DEMONSTRATION PROJECTS FOR THE DOIT COMMITTEE DECISION/ RECOMMENDATION ..................................................... 28

8.1 Jefferson Proving Ground, Indiana .......................... 31

8.1.1 Purpose/Goals of Demonstration ................................. 32 


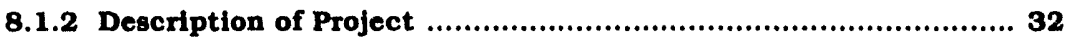

8.1.3 Organization/Management ............................................... 32

8.1.4 Timing/Schedule of Activities ..................................... 32

8.1.5 Estimated Costs /Funding Status .................................. 33

8.1.6 Selection Criteria .......................................................... 33

8.2 Yuma Proving Ground, Arizona ........................... 35

8.2.1 Purpose/Goals of Demonstration ..................................... 35

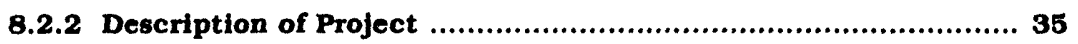

8.2.3 Organization/Management ........................................ 35

8.2.4 Timing/Schedule of Activities ...................................... 36

8.2.5 Estimated Costs/Funding Status ................................. 36

8.2.6 Selection Criteria ........................................................ 36

8.3 Fort Ord, California .......................................... 38

8.3.1 Purpose/Goals of Demonstration .................................. 38

8.3.2 Description of Project .............................................. 39

8.3.3 Organization/Management ....................................... 39

8.3.4 Timing/Schedule of Activities ................................... 39

8.3.5 Estimated Costs/Funding Status ................................. 39

8.3.6 Selection Criteria ........................................................ 40

8.4 Kaho'olawe Island, HI ..................................... 43

8.4.1 Purpose/Goals of Demonstration .................................. 43

8.4.2 Description of Project ............................................... 43

8.4.3 Organization/Management ........................................ 44

8.4.4 Timing/Schedule of Activities ....................................... 44

8.4.5 Estimated Costs/Funding Status ...................................... 44

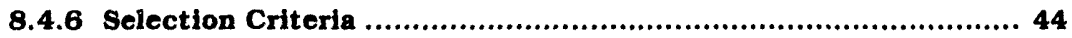

8.5 Castle Air Force Base, CA................................. 47

8.5.1 Purpose/Goals of Demonstration .................................... 47

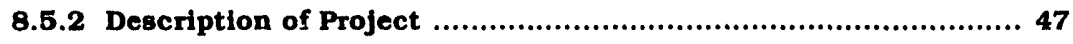

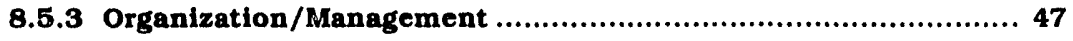


8.5.4 Timing/Schedule of Activities ................................... 48

8.5.5 Estimated Costs/Funding Status .................................. 48

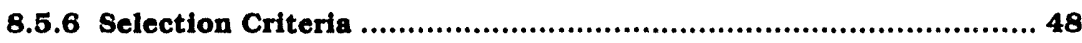

8.6 Sierra Army Depot, California ................................ 50

8.6.1 Purpose/Goals of Demonstration .......................................50

8.6.2 Description of Project ...................................................50

8.6.3 Organization/Management ..........................................5 51

8.6.4 Timing/Schedule of Activities ..........................................51

8.6.5 Estimated Costs/Funding Status ....................................... 51

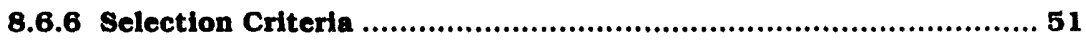

8.7 Black Hills Ordnance Depot, South Dakota.................. 54

8.7.1 Purpose/Goals of Demonstration ....................................... 54

8.7.2 Description of Project ..................................................... 54

8.7.3 Organization/Management ............................................... 54

8.7.4 Timing/Schedile of Activities .....................................54

8.7.5 Estimated Costs/Funding Status .................................. 54

8.7.6 Selection Criteria ....................................................... 54

8.8 Sunflower Army Ammunition Plant, Lawrence, Kansas ..... 56

8.8.1 Purpose/Goals of Demonstration ......................................56

8.8.2 Description of Project .................................................

8.8.3 Organization/Management ........................................ 57

8.8.4 Timing/Schedule of Activities ......................................... 57

8.8.5 Estimated Costs/Funding Status .................................... 57

8.8.6 Selection Criteria .......................................................57

8.9 Delta Range, Alaska, and Davis Range, Colorado ............ 60

\section{APPENDICES}

Appendix A - National Department of Defense Environmental Technology Sites Program for Energetics under the Strategic Environmental Research and Development Program

Appendix B - Working Group List 


\section{EXECUTIVE SUMMARY}

This report presents the findings of the Military Munitions Waste Working Group in its effort to achieve the goals directed under the Federal Advisory Committee to Develop On-Site Innovative Technologies (DOIT Committee) for environmental restoration and waste management.

As a result of military base closures after each major conflict and previously acceptable disposal practices, millions of acres of nonDepartment of Defense Federal lands and State, tribal, and private lands are potentially contaminated with ordnance explosive waste. Many of these lands are now accessible to the general public and could pose a risk to the public's health and safety. Therefore, an effort should be miade to develop, demonstrate, and field technologies which will reduce the public's risk in a better, faster, safer, and more cost effective manner than provided by current technologies.

\section{Waste Stream Areas of Concern}

The Military Munitions Waste Working Group identified the following seven areas of concern associated with the ordnance (energetics) waste stream:

1. Unexploded ordnance

- Stockpiled

- Disposed - at known locations, i.e., disposal pits

- Discharged - impact areas, unknown disposal sites

2. Contaminated media

3. Chemical sureties/weapons

4. Biological weapons

5. Munitions productior.

6. Depleted uranium

7. Rocket motor and fuel disposal (open burn/open detonation)

Because of time constraints, the Military Munitions Waste Working Group has focused on unexploded ordnance and contaminated media with the understanding that remaining waste streams will be considered as time permits. 


\section{Barriers and Shortcomings}

The current approaches, processes, and technologies for locating, identifying, and remediating ordnance waste were reviewed and weaknesses analyzed. The Military Munitions Waste Working Group found that the Department of Defense and the Department of Energy are already undertaking major programs to address the technological shortcomings. The approaches and processes shortcomings appear to be receiving less emphasis. These are areas that the Military $\mathrm{Mu}$ nitions Waste Working Group identified where the DOIT Committee could provide the greatest "value added" for environmental restoration and waste management of ordnance-related problems.

The Military Munitions Waste Working Group identified the following specific problem areas:

1. Barriers: Identified barriers are divided into two categories, regulatory/institutional and technical. Many of the barriers were found to affect all four working groups, for example. high permitting costs, disincentives for use of innovative technologies, liability, and procurement.

Regulatory/Institutional Barriers

- Procurement restrictions.

- Lack of regulations for remediation of unexploded ordnance.

- Misapplication of existing hazardous waste regulations to unexploded ordnance.

- Limited effectiveness of deed restrictions to protect future land users.

- Uncertainty as to how to assess and manage risk.

- Reluctance to award contracts or select/recommend technological approaches where there is a perceived risk in promoting a new approach, i.e., the decisionmaker gets no reward for an approach that produces good results with new technology.

- Lack of Environmental Protection Agency grant funds to process Research Development and Demonstration permits or Hazardous Solid Waste Amendment reviews.

- Placement of untrained/unqualified personnel in key roles and as decisionmakers who decide what actions should/should not take place.

- Classified technologies and information not available to solve unclassified problems. 
Technological Barriers

- Sensitivity to clutter of unexploded ordnance detection equipment.

- Size and mobility of equipment, e.g., terrain limitations.

- Inability of sensors to look at large areas cheaply.

- Inadequate trained labor force.

2. Additional shortcomings include:

- Lack of early involvement of stakeholders.

- Lack of a uniformly accepted data base for information sharing.

\section{Potential Actions to Overcome Barriers and Shortcomings}

1. Provide funding to support early stakeholder involvement.

2. Recommend Comprehensive Environmental Response, Compensation, and Liability Act reauthorization include specific requirements for remediation of unexploded ordnance contaminated sites.

3. Recommend that the National Contingency Plan be modified to specifically address ordnance contamination.

4. Recommend the Department of Defense issue policy directives that clarify the waste munitions versus hazardous substance response issues.

5. Recommend an Ordnance Committee be appointed to advise the National Response Team on matters concerning ordnance contaminated sites.

6. Establish regulations for restoration of sites contaminated with unexploded ordnance.

7. Streamline procurement requirements.

8. Provide incentives for use of innovative technologies.

9. Reduce the threat of enforcement action if a technology does not reach its objective.

10. Establish a listing of existing data bases for information and reports on ordnance and explosive waste detection, identification, and remediation. If this listing does not 
meet the requirements of the organizations working with ordnance and explosive waste, encourage the establishment of an "Ordnance Remediation Information and Analysis Center."

11. Encourage and support technology development and training.

\section{Demonstration Selection Criteria}

The Military Munitions Waste Working Group developed demonstration selection criteria based on the Ad Hoc Committee's criteria, with additional criteria the group members thought appropriate. The criteria include site, technology, evaluation and contractor categories.

\section{Identified Demonstration Sites}

Eight sites were identified as the initial potential demonstration for consideration by DOIT sites based on the selection criteria and ongoing Department of Defense research and development or technology demonstrations. These sites will be augmented as appropriate to provide a full range of sites to meet the DOIT Committee's demonstration goals.

The technological innovations in the field of ordnance explosive waste detection, identification, and remediation appear to be more evolutionary than revolutionary. The primary issues are the abilities of the technology and operators to perform as advertised and to provide all stakeholders with an understanding of the limitations and uncertainties involved with remediation. Therefore, stringent test situations need to be established to evaluate the effectiveness and efficiency of the existing systems and evolutionary improvements to these systems. These results must be repeatable to be accepted by the scientific and stakeholder communities.

We have identified the need for two test/demonstration site categories:

- Controlled test sites are designed and constructed to replicate actual field situations with all parameters precisely known, using inert munitions and munitions waste. These sites will be used to accurately evaluate the test results from technologies in research and development.

- Uncontrolled demonstration sites are sites with actual contamination where most, but probably not all, of the contaminant characteristics are known. Evaluating the effectiveness and efficiency of the demonstrated technologies will be less accurate. These sites provide a variety of environmental settings in which to demonstrate technolo- 
gies which have already been proven under controlled test site environmental conditions. These sites shall have explosives safety controls established to protect authorized observers during the conduct of the demonstrations.

Both site categories are suitable for demonstration of the DOIT clean up approaches and methodologies, including stakeholder involvement.

Documentation of the tests and demonstrations at both the controlled and uncontrolled sites will provide credentials for the technology and the company. This documentation will provide the information necessary for a site manager to proceed with conf:dence when contracting for innovative technologies.

The initial eight sites for DOIT consideration are:

- Jefferson Proving Ground, Indiana: FY 1995 Army base closure. Research and development technology testing/demonstration for subsurface unexploded ordnance.

- Yuma Proving Ground, Arizona: Active Army facility. Research and development and applied technology testing/demonstration for surface unexploded ordnance.

- Fort Ord, California: FY 1995 Army base closure. Applied technology demonstration for contaminated media and surface and subsurface unexploded ordnance.

- Kaho'olawe Island, Hawaii: Navy formerly used Defense sites. Applied technology demonstration for contaminated media and surface and subsurface and underwater unexploded ordnance.

- Castle Air Force Base, California: FY 1995 Air Force base closure. Research and development and applied technology testing/demonstration for contaminated media and subsurface unexploded ordnance.

- Sierra Army Depot, California: Active Army demilitarization facility. Research and development and applied technology testing/demonstration for contaminated media, demilitarization processes, and subsurface and underwater unexploded ordnance.

- Black Hills Ordnance Depot, South Dakota: Army formerly used Defense site. Applied technology demonstration for surface and subsurface unexploded ordnance. 
- Sunflower Army Ammunition Plant, Kansas: Partially active and partially shut down Army ammunition manufacturing facility. Research and development and applied technology testing/demonstration for contaminated media.

\section{Subsequent Reporting}

This report has been written as a "living document." Working Group's efforts not included in this report, e.g., review of the Department of Defense's National Test Bed concept, will be provided as an attachment. A full report will be made available when appropriate. 


\subsection{INTRODUCTION}

Over the span of history, military forces have trained and fought on this continent, resulting in millions of rounds of unexploded ordnance left on and in the land and under water. Live Civil War munitions found in Virginia adorn fireplace mantlepieces. Live World War I chemical munitions are found in a subdivision in Washington, D.C. Live World War II munitions are picked up in the deserts of California, Arizona, and Utah by souvenir hunters. Hunters "plink" at Korean War-vintage munitions left on a former artillery range.

Undocumented burial of obsolete munitions was an a' -epted practice into the Vietnarn perioc. Historically, after each of this country's major military conflicts, the installations built to accommodate training requirements were closed and the lands transferred to other Federal agencies, States. or the private sector. Today, subdivisions are built on top in abandoned military installations, and recreational activities take place on former maneuver areas and ranges. A growing population increases the opportunity for contact with munitions waste, especially unexploded ordnance and buried munitions. Contaminants in soil and water also present problems when they migrate offsite.

In the aftermath of the Cold War, we are once again in a period of closing and transferring lands from Department of Defense control. Lands that were formerly used as defense sites are being reused in a variety of ways that put citizens at risk because of then acceptable past practices. It is estimated that more than 2-million ordnance contaminated acres are managed by the Bureau of Land Management. Forest Service, and Fish and Wildlife Service and on lands belonging to Indian Nations, States, and the private sector. For most installation closings in the past, the surface was "cleaned" and items not suitable for reuse were buried. The question now becomes: What are the risks on and in these lands and waters, and what is the best way to reduce or manage these risks?

Until recently, little effort was put into cleaning up what could not be seen on the surface. Remediation of ordnance and explosives wastecontaminated media receives benefits from the many technologies that the Environmental Protection Agency and others have developed over the past two decades for similar contaminants. Industry has developed specialized surface- and ground-penetrating sensors. However, the technologies related to unexploded ordnance are a different matter. The technology used for locating military munitions has not progressed much beyond the trained individual and backpack systems of World War II. The current suite of technologies is not suitable for sensing tens of thousands of acres in a variety of environmental settings.

Frustration over seemingly little progress in development and deployment of technologies to accomplish the cleanup task in a better, safer, 
quicker, and more cost effective manner has led to the formation of a joint Federal-State effort named the Federal Advisory Committee for the Development of On-site Innovative Technologies (DOIT Committee) for environmental restoration and waste management.

The DOIT Committee was chartered through a memorandum of understanding among the Western Governors' Association; the Departments of Defense, Energy, and Interior; and the Environmental Protection Agency. The Military Munitions Waste Working Group, one of four topical groups established by the DOIT Committee, was chartered to investigate the development of onsite innovative technology for environmental restoration and waste management of military munitions waste, also known as ordnance and explosives waste or "energetics."

The initial task of the Military Munitions Waste Working Group was to determine the scope of the issue and discover what activity was already underway in this area (a membership list is attached in Appendix B). The very wide array of disparate issues found lead the Military Munitions Waste Working Group to initially limit its focus to unexploded ordnance, contaminated media, and demilitarization of munitions. The Military Munitions Waste Working Group also found a great deal of activity within the Department of Defense, the Department of Energy, and the commercial sector that was directly applicable to ordnance and explosives waste remediation.

The first issue the Military Munitions Waste Working Group considered was: What is the "value added" that the DOIT Committee could bring to any partnership? The second issue was: Should the Military Munitions Waste Working Group focus on specific technologies, or should it focus on the process of developing and deploying innovative technology? With increased knowledge of the problems, the state of the technology, and the development and testing programs already underway, the working group chose to follow the "process path." The working group determined there would be more value added by concentrating on the process of developing and deploying technology rather than on efforts to develop a few promising technology "enhancements." Concentrating efforts on developing a few technologies was too confining and duplicative of the Department of Defense programs already underway, additionally, the timeframe of the memo of understanding limited progress only to enhancements of existing technologies rather than truly innovative breakthroughs. Following the "process path" world lead the DOIT Committee to value added in the areas of partnering, including stakeholder involvement, information sharing, and risk understanding.

The Military Munitions Waste Working Group identified the lack of stakeholder participation as a weakness in the current technology development programs. Stakeholders in the eventual cleanup of sites were not present during the development and testing stages of the technologies and methodologies to be employed. Lack of participation generally leads to resistance to "new" technologies and methods by the local community, environmental groups, State environmental 
regulators, and the commercial sector because knowledge, understanding, and ownership of decisions is missing. This impedes progress on remediation efforts. The DOIT Committee, however, can assist with the development of site-specific stakeholder groups that will work for understanding and formulation of remediation actions satisfactory to all concerned.

The Military Munitions Waste Working Group plans to work toward improving stakeholder participation by doing additional work in the area of information data bases by compiling a list of existing sources. If this proves unsatisfactory, the working group would like the DOIT Committee to pursue the option of an agency or institution establishing a an "Ordnance Remediation Information and Analysis Center."

The understanding of risk associated with munitions waste is little known outside the explosives ordnance disposal community. Armed with information concerning issues such as risk, risk assessment methodology, site remediation prioritization based on risk, cost/risk reduction ratios, and risk/use of land, all stakeholders can make informed decisions concerning site restoration.

A scientific approach to testing technologies and systems in a controlled setting that could provide validated results was determined to be the best way to proceed with technology demonstrations. Many companies and consultants offer an array of technologies and systems to solve the ordnance and explosives waste problems. The Military Munitions Waste Working Group realized that there is, however, no appropriate way to validate the effectiveness and efficiency of these systems. To pick a site and do a demonstration without being able to evaluate the results is worse than useless - it is a waste of time and money.

The Department of Defense has reached the same conclusion and has proposed and received funding to establish a National Department of Defense Environmental Technology Sites Program for Energetics under the Strategic Environmental Research and Development Program (See Appendix A). The Military Munitions Waste Working Group supports this proposal and will work closely with the Department of Defense program office in selecting sites, test protocols, etc.

The Military Munitions Waste Working Group has initially identified eight potential sites for consideration in partnering with the Department of Defense agencies for demonstrations of stakeholder participation and technology. The working group attempted to select a spectrum of sites that represent major waste management problem areas and the variety of site problems. This report focuses on the criteria used to select these sites and provides background information on the sites.

This document is a living report that will change over time. Its preparation has been a major learning experience for the working group members, who should be considered as regional stakeholders. As knowledge grows, views may change. For example, additional demonstration sites will be added in the future, and some sites currently recommended may be dropped; two sites suggested at our May 1993 meeting have already been dropped. 


\subsection{MILITARY MUNITIONS WASTE WORKING GROUP CHARTER}

The mission of the Military Munitions Waste Working Group is to support the DOIT Committee in its efforts to expedite development and commercialization of innovative technologies for the investigation, remediation, management, and minimization of environmental waste at various former and current defense sites where military munitions contaminants exist. This mission will be accomplished through fact finding and information gathering related to site and technology demonstration criteria; through issue identification; and by promoting technology development, deployment, and commercialization. The Military Munitions Waste Working Group will also assist the DOIT Committee in establishing enduring partnerships with stakeholders to jointly advance new environmental cleanup technologies. At the direction of the DOIT Committee, the working group will identify approaches to assist the DOIT Committee in tracking the effectiveness and efficiency of demonstration projects.

\subsection{DESCRIPTION OF PRIORITY WASTE STREAM PROBLEMS}

Munitions waste is a threat to human health and safety and to the general environment. This waste is found on formerly used defense sites that may now be under the control of a non-Department of Defense agency, Indian Nation, a State government, or the private sector; on former and current munitions manufacturing sites; on installations listed for base closure; and on installations that have an ongoing military mission.

In May 1993, the Military Munitions Waste Working Group identified seven problem areas associated with the presence and cleanup of facilities where unexploded ordnance and media contaminated with materials from the manufacture and use of munitions may exist. The seven primary areas of concern are unexploded ordnance, contaminated media, chemical sureties/weapons, biological weapons, munitions production, remediation of depleted uranium, and rocket motor and fuel disposal. 


\subsection{Unexploded Ordnance}

\subsubsection{Stockpiled Material in Magazine}

One traditional treatment method for demilitarization of conventional ordnance is open burn/open detonation. Incomplete destruction may produce unacceptable air emissions and contaminate soil and water resources (surface and ground water). An innovative technology to eliminate open burn/open detonation is needed.

\subsubsection{Disposed (known areas of disposal, e.g., disposal pits)}

Prior to the Vietnam conflict, disposal of ordnance by burial was a common and acceptable disposal practice. Records of these areas are incomplete. Past disposal areas may not now be recognizable as such. In some cases, disposal areas have been discovered in lands accessible to the general population. As with the unknown discharge areas, the explosive potential represents an acute threat to human health and the environment. Means to locate buried ordnance disposal sites are required.

\subsubsection{Discharged (unknown areas of disposal, e.g., ranges)}

These areas are characteristically large, and unexploded ordnance and metal debris are widely scattered. The extent of soil contaminated with explosive compounds and fragments is equally widespread. Locating unexploded ordnance, especially those that are subsurface or under water, is subject to uncertainties and can be very costly. The unknown presence and acute explosive potential adds a significant risk to any field activity where unexploded ordnance may exist. Additionally, remediation of subsurface munitions waste can be environmentally destructive. In high-density areas (more than 1000 items per acre), area recovery is used: the soil is excavated to the required depth, sifted for ordnance items, and then replaced and replanted. A less destructive means of locating and collecting discharged unexploded ordnance is necessary.

\subsection{Contaminated Media}

Soil, surface, and ground water have been contaminated with explosive compounds and their decomposition products. Metal fragments are also widely spread in open burn/open detonation areas and on bombing/firing ranges. In many cases, the area that has been contaminated with explosive and metal debris is very exstensive. Time and cost for restoration are considerable. Prior to reuse of the area and to protect resources from contamination, areas where these contaminants exist must be remediated. Advanced technologies are needed to identify areas of contamination in a more cost effective and accelerated manner and to remediate soils in situ without excavation and the resulting environmental destruction. 


\subsection{Chemical Sureties/Weapons}

As with conventional ordnance, burial of chemical weapons was an accepted disposal practice. The lack of accurate disposal records and the acute threat represent significant challenges to the restoration of lands that may contain buried chemical agents. Leaking stockpiles of chemical weapons also represent a threat to human health and the environment. While restrictions exist that prevent private handling of chemical ordnance, improvements in locating unexploded ordnance and technologies for detecting residues are needed.

\subsection{Biological Weapons (waste handling only)}

During and after World War II, many biological weapons were developed. These weapons and weapon systems ranged from "incendiary bats" to highly toxic bacterial and viral agents. Although never used against an enemy force, complete weapon systems were developed. The status of the development, testing, storage and demilitarization facilities are unknown. Since these agents can be extremely hazardous, the complete characterization of the remediation situation is important. Technologies must be available to render any remaining problem areas safe.

\subsection{Munitions Production}

\subsubsection{Environmental Restoration at a Site}

The problem is similar to that of contaminated media. It is unknown whether there may also be previously acceptable or unintentional disposal of unexploded ordnance at manufacturing sites as described earlier in this section.

\subsubsection{Waste Management with Discrete Stream}

Munitions production by the military and the private sector generate considerable amounts of hazardous waste. The management of ongoing waste streams associated with the production of munitions has been characterized by storage, transformation, and disposal. Recently efforts have been focused on recovery technologies and waste minimization. This redirection provides great opportunities for development of innovative technologies that could be carried into media restoration efforts.

\subsection{Remediation of Depleted Uranium}

Because of its unique characteristics (i.e., mass and availability), depleted uranium is used as a penetrator mechanism in 30 millimeter (mm) munitions and, in some cases, as a shielding material for 
armored vehicles. When these munitions impact a target or shielding, oxidation occurs with fragmentation and subsequent deposition of depleted uranium at the target site. Low levels of radiation are found at the site, and media can become contaminated with depleted uranium fragments and projectiles. Alpha particles are of the most concern since they can become airborne in wind-driven dust and can be inhaled. Technology is needed to neutralize, stabilize, or contain these materials in areas such as target ranges where the use of depleted uranium occurred.

\subsection{Rocket Motor and Fuel Disposal}

With the reduction of military forces in the United States and worldwide, rocket motors are being removed from service and reduced in number. The motors are being shipped to munitions depots for storage and for disposal. The disposal method presently used is open burn/open detonation, which can result in explosions that scatter motor parts and contaminate the environment with unburned propellant. An effective and environmentally sound alternative to open burn/open detonation is required.

\subsection{SHORTCOMINGS OF EXISTING APPROACHES, PROCESSES, AND TECHNOLOGIES}

\subsection{Approaches}

\subsubsection{Stakeholder Participation}

There is general group consensus on the need to change the type of and schedule for public input on environmental remediation decisions. However, there is also some institutional sensitivity to increasing the public's access to cleanup discussions. Governmental agencies have widely divergent approaches and programs related to public participation.

The community of stakeholders, including most regulators, has not had the opportunity to be informed concerning unexploded ordnance, stored munitions, or media contaminated by the wastes produced in manufacturing munitions. Safety and security, as well as environmental factors, must be considered. Regulators and communities will be thrust into discussions and decision making without proper orientation or education regarding these unique wastes. Neighbors of rnunition plants or gunnery ranges may be cognizant of the current 
mission at these facilities; however, they are facing the specter of installation closures and altered priorities at federal enclaves. There has not been a public forum for the exchange of information regarding the remediation of lands contaminated with unexploded ordnance or the energetic materials needed for their production.

\subsubsection{Information Sharing}

Regulatory decisions and stakeholder involvement cannot function in a vacuum. If there is to be informed input from communities, and if regulatory impediments are to be reduced, a program for the dissemination of information regarding the production, use, demilitarization, and disposal of munitions must be established.

\subsection{Processes}

\subsubsection{Decisionmakers Disincentive}

One of the barriers to the use of innovative technologies is the reluctance of those that award contracts or select/recommend technological approaches to accept the perceived risk in promoting a new approach. In addition, there is currently no incentive for a decisionmaker to use an innovative approach. The decisionmaker gets no reward for an approach that produces good results from new technology. If, on the other hand, the technology or approach does not meet expectations or projections, there is a disincentive.

\subsubsection{Inadequate and Inappropriate Regulations}

The world of ordnance remediation, removals, and response actions is progressing faster than the regulatory framework that should have been implemented shortly after the Superfund Amendments and Reauthorization Act was published. The execution of the ordnance remediation program has overtaken the Environmental Protection Agency and Department of Defense policy/ guidance to execution agents who are assigned ordnance and/or chemical munitions cleanup responsibilities. This results in regulatory ambiguities that cause those individuals responsible for cleanup efforts to fear damage to their careers and the potential for fines and penalties for executing in conformance with the norms and practices of explosives safety. These personal liabilities are grossly unfair to those who risk their lives to give us a cleaner and safer environment. Project delay, cost growth, and potential technical inferiority are certain results of these deficiencies in remedial action policy.

The Superfund Amendments and Reauthorization Act established the Defense Environmental Restoration Program in 1986. Under that law, the Secretary of Defense was given authority to address inactive or abandoned military sites that are contaminated with hazardous substances and sites that are contaminated with unexploded ordnance. The goals of the Defense Environmental Restoration Program are contained in separate, numbered paragraphs and are explicitly distinct under the law. 
The magnitude of the potential cleanup of ordnance contamination at former defense sites (over 1000 sites) requires the promulgation of regulations that implement the second goal of Defense Environmental Restoration Program (10. U.S.C. 2701 et seq.) so that the cleanups can be uniformly and effectively performed. It also requires that the National Contingency Plan be revised to clearly define the roles and responsibilities of the Department of Defense as the removal response authority for incidents involving munitions, both conventional and chemical. Additionally, roles of the regulatory community must be clearly defined.

No implementing rules were promulgated under the second goal of the Defense Environmental Restoration Program, and current application of rules for hazardous substances to the response action for ordnance sites is inappropriate. It causes inefficiency, delay, and increased costs. Recent problems at Spring Valley and other formerly used Defense sites confirm the need for clarifying action.

This need for clarification must also be addressed by the Environmental Protection Agency, which has been directed to determine when munitions become a hazardous substance under the Federal Facilities Compliance Act. This determination will be helpful to the response personnel if it results in a clear delineation of which rules apply in a given situation. Explosives safety logically must be the controlling factor until the imminent hazard is eliminated. This would clarify the point at which munitions are subject to permitting requirements of the Resource Conservation and Recovery Act.

Because ordnance poses an imminent endangerment to the public that is clearly distinct from hazards posed by traditional hazardous substances, there is a need to establish an ordnance committee on the National Response Team. Through this team, ordnance issues can be discussed in a high-level forum that will pave the way for understanding throughout the environmental community, regulators, and response agencies.

\subsection{Technologies}

\subsubsection{Unexploded Ordnance}

Remediation of land and underwater areas that have been contaminated with military munitions waste lalso known as ordnance explosive waste], which includes unexploded ordnance, involves a number of separate activities, each of which makes use of various technologies. Some of these activities, the technologies that support them, and their shortcomings of the technologies are briefly described in this section. Some innovative technologies that hold promise for improved performance will be discussed in a later section of this report. 


\section{Detection and Identification}

Contaminating munitions waste items or material, which may be located on or below the ground surface or under water, must be detected, located, and, if possible, identified during munitions waste survey or remediation operations. Surface searches are most often conducted by personnel walking in line abreast over the ground. Purely visual surface searches usually yield only mediocre success [measured in terms of the search-effectiveness probability]. Detection instruments - most commonly the magnetometer - are typically used by the search team to complement their vision. The principal difficulties associated with searching a surface for munitions waste contamination occur when surface or shallow buried hazards make a walking search especially dangcrous to the search team, and when the search area is large. The first difficulty can be resolved by removing the requirement for personnel on the ground. This might be accomplished by developing platforms and instruments for aerial survey. Recent advances in robotics suggest that inexpensive, autonomous robots might also be developed for this purpose.

When the search area is large, interest is often concentrated on cletermining whether or not a munitions waste contamination problem even exists. If it does exist, interest is then focused on which subarea(s) of the site is contaminated. Search precision could be sacrificed for speed: detailed exploration on the ground would be conducted if a rapid surface search indicated the likelihood of munitions waste being present. There is an evident need for better, faster. and more reliable methods for surface surveys of contaminated areas or areas where contamination is only suspected. Once again, the development of platforms and instruments for aerial survey would appear to be appropriate. Airborne radar surveys of large areas may constitute a rapid and inexpensive means of locating surface munitions. Airborne infrared sensors that can detect the small temperature differences between surface metallic objects and the soil ${ }^{\prime}$ may also prove useful for this purpose.

Searches for buried hazardous items are conducted by teams of individuals walking over ground and using a variety of detection instruments. The most important of these is the magnetometer, which measures local fluctuations of the Earth's magnetic field that are caused by the presence of ferrous-metallic objects; the electromagnetic induction detector, or "metal detector," which responds to the nearby presence of electrically conductive material; and groundpenetrating radar systems, which transmit pulses of electromagnetic energy into the soil and receive the signals reflected from the buried objects. Under certain conditions, other more exotic sensors, including infrared imaging systems, trace gas analyzers ("sniffers"), and

\footnotetext{
'These temperature differences, which are most pronounced at dawn and dusk, result from differences between the thermal properties of the soil and the surface objects.
} 
nuclear activation detectors, can be used. Unfortunately, typical burial depths and construction of munitions generally render these instruments ineffective.

In general, the sensitivity of the most commonly used subsurface detection instruments appears to be adequate to detect objects of sizes and at depths of greatest interest, at least under ideal conditions. The principal technical shortcomings of existing sensors are (1) slow sensor data collection and (2) contamination with clutter signals arising from sources such as shrapnel, communications wire, and locally magnetized soils (for magnetometers). The depth resolution of magnetometers and electromagnetic induction detectors is inadequate for reasons associated $w$ th the fundamental physics of these instruments. Improved mathematical techniques for fusion and computer processing of the sensor data may, however, improve both the horizontal and the depth resolution attainable with these sensors if a rapid and convenient method of acquiring the sensor data can be developed. Ground-penetrating radar systems are limited in the depths to which they can "see;" further, they tend to be somewhat delicate instruments that work best on smooth terrain, and they are not particularly well suited for use under rugged field conditions. Also, to date there is little evidence that airborne radars (or other sensors) can robustly detect buried ordnance under any but the most favorable conditions. ${ }^{2}$

An additional detection problem arises when there exists the possibility that unexploded ordnance contamination may include chemical warheads as well as conventional high-explosive bombs or shells. It is not presently possible to determine whether a detected item contains chemical warfare material until it is exposed and inspected, and even then it may be difficult to determine. The lack of a fieldable instrument that could make this distinction constitutes an important shortcoming of present technology. We remark, however, that research has been conducted at Lawrence Livermore National Laboratory and Idaho National Engineering Laboratory on the problem of distinguishing chemical from highexplosive munitions in the context of treaty verification. The potential applicability of this work to the problem of making such distinctions in remediation operations under field conditions should be investigated.

The problem of detecting and locating underwater unexploded ordnance contamination is unique. In some ways, the problem is easier, in others it is compounded. The viscous drag forces exerted on, for example, a bomb by its passage through water tend to reduce its depth of penetration into the bottom. Thus, most underwater unexploded ordnance will be found on, or very close

\footnotetext{
${ }^{2}$ Conditions favorable to airborne radar systems are extremely dry soil, smooth terrain, and limited surface vegetation. Some desert regions of the southwestern united States could be surveyed (to a degree) by airborne radars at certain times of the year.
} 
to, the bottom. In addition, the problems of shrapnel and other clutter sources are not nearly so severe as those occurring on a land target range. On the other hand, marine growth can obscure an item lying on the bottom, making its visual detection difficult.

Conventional methods for underwater survey use teams of scuba divers. Search rates obtained through these methods are slow between 12 and 16 diver-hours per acre are requested - and search costs are high, typically several thousands of dollars per acre. The cost increases rapidly with search depth because of the increasingly severe limitations on divers' working time.

More efficient techniques for underwater search need to be developed. These techniques should make use of integrated suites of instruments, including visual (video cameras and laser line scanning equipment) and other sensors (e.g., magnetometer arrays) to support the search and reduce the need for divers. Boat-towed platforms rather than free swimming underwater vehicles would appear to be preferable for integrated underwater survey systems.

\section{Mapping}

Locations of contamination must be precisely marked and mapped so they can be relocated easily. Efficiency in survey and remediation operations is best served through the division of labor, i.e., when the detection and location task is performed separately from access and recovery, which is itself separate from the neutralization or demilitarization of the recovered items. In practice, therefore, an optimal capability would be to quickly mark and later relocate a detection "hit" with an accuracy of a few tens of centimeters, both horizontally and vertically, in a large (thousands of acres) area of reasonably rough terrain. The requisite horizontal resolution might be obtainable with a differential Global Positioning System; the vertical resolution is presently not reachable with most detection instruments.

\section{Removal}

Access to buried contaminating items is usually gained by excavating the locations of detector "hits." Excavation using machinery must give way to cautious and tedious hand excavation as the object is approached. Current detection and location instruments do not provide a sufficiently accurate estimate of the target depth to make the access and removal process efficient. Improved sensor data collection and processing might provide much more accurate estimates of target depth than are presently possible.

\section{Neutralization or Demilitarization}

Hazardous items may be neutralized by detonation in place, or they may be removed to a demilitarization facility located on, or at some distance from, the site undergoing remediation. Detonation in place. which is often the only safe method for neutralization of explosive items, carries with it concerns for blast, noise, and vapor containment. Blast containment coverings tend to be heavy, bulky, and 
difficult to position. Sand tamping for noise control is labor intensive and time consuming, and it creates problems with dust. Reliable mathematical models for predicting the noise impact on neighboring communities do not appear to be available, although their development should not be particularly difficult.

Demilitarization of removed explosive items is typically performed using incinerators or furnaces. Because of the necessity of preventing potentially harmful vapors from entering the atmosphere from these systems, air scrubbers are required. These items are expensive, often costing in excess of a million dollars. A need exists for rapid, inexpensive, and environmentally benign methods for demilitarization of recovered munitions. ${ }^{3}$

A problem is also associated with abandoned open burn/open detonation areas at which neutralization and demilitarization were carried out in the past without stringent environmental controls. The debris remaining in these areas can pose both explosive and toxic chemical threats. A need exists for the adaptation of present methods of soil cleaning (which are typically applied to the removal of hydrocarbon or heavy-metal contamination from soil) and development of new approaches to address the problem of removing specific explosive and toxic compounds from soils. Such approaches could be applied both to the remediation of abandoned open burn/open detonation sites and to that of other areas (including former range areas) contaminated by explosive compounds and their decomposition products.

\subsection{Contaminated Media}

(Information for this section is not available at this time.)

\footnotetext{
'A special problem arises when disposing of chemical warfare material (also called chemical surety' material). Such material is incinerated in special furnaces. Only three of these facilities exist - the Rocky Mountain Arsenal, the Chemical Mumitions Disposal System (Tooele, Utah), and the Johnston Atoll Chemical Agent Disposal System.
} 


\subsection{INNOVATIVE APPROACHES, PROCESSES, AND TECHNOLOGIES}

\subsection{Approaches}

\subsubsection{Stakeholder Participation}

The Federal Advisory Committee for the Development of On-site Innovative Technologies (DOIT) project includes a commitment to open the environmental remediation decisionmaking processes to broader public involvement. At every planning level, care has been taken to represent multiple viewpoints. Adoption of the Stakeholder Outreach and Participation Plan provided a blueprint for broad representation in the definition phases and subsequent technology search and demonstration phases. The Military Munitions Waste Working Group includes representatives from varying backgrounds as prescribed by the DOIT project.

Demonstrations ultimately recommended by the DOIT Committee will include broad stakeholder participation. Collaboration with existing groups, wherever appropriate, will be an important component in a successful demonstration. The Military Munitions Waste Working Group will have a role in putting in place a stakeholder plan that reflects the project goals.

\subsubsection{Information Sharing Information Resources}

The Military Munitions Waste Working Group identified as a current problem a lack of readily available information on ordnance explosives waste detection and remediation technology and test results for the technology. Members suggested that the Western Governors' Association sponsor a consolidated data base for this topic area. Others said they regularly access a number of existing data bases.

The lack of a consolidated data base has been identified as a process shortcoming of ordnance explosives waste management. Therefore, the Military Munitions Waste Working Group intends to poll its mailing list of members and observers to develop a list of existing data bases, how to access them, and the key search words. If this effort does not appear to be satisfactory, the working group will pursue the possibility of a government agency, company or university willing to develop and maintain such a data base.

A preliminary study has led to the following conclusions.

\section{Contaminated Media}

Commercial public data bases and information services can provide most available documents on treatment technology, chemical 
and biological issues, and social and health-related aspects of the Defense Environmental Restoration Program.

\section{Unexploded Ordnance}

Restricted data bases such as the Defense Technical Information Center can provide, directly to certain authorized users, available documents on target location and characterization, specific hardware performance, and general ordnance handling procedures. However, because of the potential for military applications or use by unfriend!ies, much of the information will be available only on an as. needed. case-by-case basis and is releasible only by the contributor to the Defense Technical Information Center of the technical data. The formal process to obtain restricted data is well defined and generally available to potential authorized users.

\section{Risk Understanding and Acceptance}

A major information shortcoming identified by the Military Muritions Waste Working Group was the lack of stakeholder understanding of the risks associated with ordnance explosive waste and the relationship among risk, the possible reuse options for contaminated lands, and the limitations of current technology. The working group feels that this an is area where the DOIT Committee can add value to the Federal/State partnership through education of stakeholders. The working group would like to pursue this topic and develop a DOIT Committee information booklet that would be made available to stakeholders.

The full range of risks associated with ordnance explosive waste is not well known by the majority of stakeholders. Generally, risk may be thought of as containing the components of exposure (i.e., the chance that a person will come into contact with ordnance explosive waste) and the likelihood of an action/reaction event occurring (i.e., that the ordnance explosive waste will cause harm).

Information concerning real and perceived risks must be made available to st.3keholders. Analysis methodology must be made available to assist stakeho ders in understanding the relationship between the factors of risk reduction, technology limitations, costs, and environmental degradation. Since it is impossible technologically or financially, nor in many situations environmentally sound, to ensure 100 percent cleanup of subsurface or underwater contamination, a knowledgeable stakeholder group must reach a reasonable decision as to the degree of cleanup desired. This decision is primarily governed by balancing the desired reuse of the land against: the capabilities of availabie technology, increasing cost according to the 
amount of risk reduction as 100 percent cleanup is approached, and the increasing damage to the environment that is the result of moving closer to 100 percent cleanup.

The U.S. Army Corps of Engineers and the Department of Defense Explosives Safety Board have information on this topic and are developing more sophisticated models. A major area of methodology development is the ability to prioritize the allocation of limited Corps of Engineers assets for cleanup of formerly used Defense sites based on the risk to humans. A partnership of the DOIT Committee, the Corps of Engineers, and the Department of Defense Explosives Safety Board would be effective in providing information to stakeholders.

The following information on the prioritization of formerly used Defense sites ordnance explosive waste risk was provided by the Corps of Engineers for inclusion in this report.

\section{PRIORITIZATION OF FORMERLY USED DEFENSE SITES ORDNANCE EXPLOSIVE WASTE RISK}

Formerly used Defense sites contaminated with ordnance explosive waste can be prioritized by risk reduction and cost of remediation. There are as many as 900 formerly used Defense sites contaminated by ordnance. Currently, there is no methodology available for determining where the limited dollars available for remediation can best be spent. Three risk/cost modules are being developed to aid decisionmakers in determining which sites to remediate in which order. Because of the large number of sites that must be remediated, there must be a methodology to quantify risk/cost and prioritize the sites. The methodology being developed will assist the decisionmaker in making objective and defendable decisions on which sites should be remediated given budgetary and other constraints.

The risk/cost theoretical formulation for the dispersed site module (ranges/impact areas) is nearing completion. The formulations of the non-dispersed site (burial pits and trenches) and the water site modules are projected for completion in early 1994. The risk/cost modules will allow a decisionmaker to determine the estimated cost for risk reduction at a site.

The prioritization methodology should be complete by midyear 1994. The data necessary to operate the prioritization methodology is currently being gathered. The prioritization methodology will allow a decisionmaker to rank all sites according to the cost to reduce risk to an acceptable level, the amount of risk reduced for a given site, and by cost per risk unit reduced. This prioritization effort will allow a decision maker to make informed choices o'l the sequence in which sites are remediated, given risk reduction and budgetary constraints. 


\section{Declassification of Classified Reports and Technologies}

While the classification of technical specifications and the full capabilities of certain systems may need to remain classified, the technologies and analysis methodologies considered innovative may have been in use for years within the classified world.

The DOIT Committee does not seek, nor does it need access to, classified information, even though some members have clearances. The need is for government agencies to look at ways of assisting the DOIT Committee demonstrations and follow-on remediation efforts by providing unclassified information on systems application to a specific problem and declassified (sanitized) reports. Congress has already provided the statutory guidance to declassify systems and products. It now falls to the appropriate Federal agencies to place this guidance into practice.

\subsection{Processes}

\subsubsection{Decisionmaker Disincentives}

To promote innovative technologies and approaches to solving environmental problems, a policy change at the highest levels is recommended. A directive from agency Secretaries and Governors to encourage employment of innovative technologies will enable those that make the site decisions to do so without fear for their jobs/positions and will minimize the perceived risk of employing innovative technologies.

\subsubsection{Inadequate or Inappropriate Regulations}

The Military Munitions Waste Working Group suggests the following actions be supported by the DOIT Committee:

- A formal recommendation that the Comprehensive Environmental Response, Compensation, and Liability Act reauthorization include provisions to address the development of regulations for remediation of unexploded ordnance contaminated properties.

- Recommend that the National Contingency Plan be modified to specifically address ordnance contamination including formerly used Defense sites. The modification of the National Contingency Plan will provide a format for response to ordnance contamination sites and establish roles and responsibilities for the Department of Defense and the regulatory community. The modification should affirmatively acknowledge that authorities and responsibilities for ordnance contamination abide with the Secretary of Defense. Specific consideration must be given to the imminent threats represented by the presence of unexploded ordnance. It is expected that the Applicable. Relevant, and Appropriate Requirements process in use 
for Comprehensive Environmental Response, Compensation, and Liability Act response actions can provide an adequate forum and control for the Federal and State regulators' concerns.

- Recommend that the Department of Defense issue directives that clarify the waste munitions versus hazardous substances response issues within the Department of Defense and require National Contingency Plan compliance.

- Recommend that the Department of the Army promulgate implementing regulations through rulemaking procedures. Public input and agency comments will be essential to final rules.

- $\quad$ Recommend that an ordnance committee be appointed to advise the National Response Team on matters concerning ordnance and contaminated sites. This would foster discussion of ordance issues and development of explosives safety policies consistent with congressional mandates under Defense Environmental Restoration Program.

- $\quad$ Request a meeting between the National Response Team and the members of the Military Munitions Waste Working Group and DOIT Committee representatives to discuss issues and promote the establishment of the proposed ordance committee.

- Recommend that interim regulations be issued as soon as practical to alleviate problems occurring while final rules are being established.

\subsection{Technologies}

\subsubsection{Unexploded Ordnance}

This section describes areas of technology development presently under consideration for improvement in speed and reliability, and reduction of cost and risk, in military munitions waste remediations. Emphasis is given to, and recommendations are made regarding, the problem of detecting subsurface items of unexploded ordnance.

The detection of buried unexploded ordnance, and thus the success of range clearance operations, is driven by available sensor technology. No existing sensor can detect every ordnance item under every conceivable condition, and it is not reasonable to expect this situation to change appreciably in the near future. The physical detection methods that the Military Munitions Waste Working Group believes will be most useful in the near term are those that are presently used in the explosive ordnance demolition 
community: magnetometry and electromagnetic induction detection. These sensors are sufficiently sensitive to detect isolated buried unexploded ordnance items of sizes and at depths of greatest interest (i.e., small items near the surface and larger items at greater depths) given adequate data - that is, data taken over a sufficiently fine spatial grid. The working group, therefore, asserts that existing sensors can, in principle, be used as a basis for thorough clearance operations.

While existing sensors can perform thorough searches, they generally cannot do so efficiently. Their greatest limitation is their sensitivity to clutter. When a sensor is operated with a sensitivity that permits reliable detection, the number of false alarms associated with the simultaneous detection of harmless objects, including soil inhomogeneities and shrapnel, can be excessive. Because each potential detection must be investigated via excavation, thorough clearance is often accompanied by low efficiency and high cost. The Military Munitions Waste Working Group believes that reduction in false alarm rules is presently the area of greatest potential payoff from improving detection technology for buried unexploded ordnance.

In addition, existing sensors are labor intensive. Although there are a few recently developed semi-automated techniques, range clearance requires a team of trained sensor operators to interrogate the surface over a fine grid to detect near-surface objects. Detection of deeply buried objects, especially in a cluttered environment, is difficult without computer data acquisition and processing. Improvements in sensor data collection and processing will permit better sensor performance in the presence of clutter, enable greater speed in buried unexploded ordnance detection, and reduce both missed detections and false alarms.

On the basis of these observations, the Military Munitions Waste Working Group believes that the efficiency and cost-effectiveness of range clearance operations would be improved through technology development efforts that are focused on remedying the deficiencies outlined above. The objectives of these efforts should be to refine sensor concepts and to develop methods for efficient sensor data acquisition and processing. The outputs of such a development effort should be techrologies necessary to field a number of new range-clearance sensors and systems. Specifically, we see a need to further develop the following concepts.

\section{Smart Sensors}

False detections as a result of strong clutter signals are a major source of inefficiency in range clearance. Efforts should continue to develop data processing algorithms and sensor hardware improvements that will permit a hand-held unit, perhaps operating in conjunction with an onsite central data processing facility, to discriminate near-surface unexploded ordnance from clutter in near-real time. 


\section{Distributed Sensor Networks}

Research should be directed toward the development of (1) technology necessary to acquire simultaneous position and (2) sensor data from multiple sensors and sensor data fusion and processing algorithms necessary to permit detection and precise location of objects (especially large, deeply buried objects) with rejection of clutter.

\section{Centralized Clearance Monitoring}

An effort should be made to assemble the software and hardware that would permit a central location to monitor and record the progress of multiple, independent search activities at a given site. We expect recent improvements in Global Positioning System technology and Geographical Information System software to be especially useful in this regard.

\section{Emerging Sensor Concepts}

New sensor concepts are continually being developed, and older concepts are being modified and refined. It is appropriate to monitor and evaluate these developments for use in range clearance. The Military Munitions Waste Working Group considers the following concepts to be particularly worth examining:

- Impedance topography processing techniques for resistivity mapping data;

- Ground-penetrating radar systems with small-aperture antennas used in a mode similar to that employed in biomedical acoustic imaging;

- Small, ground-based (robotic) and stable, very-low-elevation airborne platforms for autonomous detection of unexploded ordnance; and

- Sensor fusion techniques for combining data from multiple sensors.

The costs of such a technology development effort would be negligible compared to the cost of clearing a single range of modest size. Wise investments in research can thus have a great deal of leverage in improving the efficiency and reliability, and in reducing cost and risk, of range clearance operations.

\subsubsection{Contaminated Media}

(Information for this section is not available at this time.) 


\subsection{WORK FORCE PLANNING, TRAINING, AND EDUCATION ISSUES RELATIVE TO TECHNOLOGY DEPLOYMENT AND CLEANUP}

The Nation's needs for remediation and restoration of lands and underwater areas that are contaminated with military munitions waste, including ordnance explosive waste, far outstrip the trained labor resources presently available to meet these needs. It has been said that the number of all the trained explosive ordnance demolition specialists now living is insufficient to meet the expected future demand for their services. It is unreasonable to expect that in the foreseeable future, the output of the Naval Explosive Ordnance Demolition Technology Center (where explosive ordnance demolition specialists are trained) will be increased so that such personnel will be available in the numbers required. At issue, therefore, is how to make optimal use of the available pool of trained explosive ordnance demolition specialists and how to develop an additional labor force capable of supporting this pool.

The basis for a supporting labor force already exists, or soon will exist, near the great majority of sites that will require munitions waste remediation. The negative economic effect on local communities of base closures would be alleviated to a considerable degree if laid off workers were retrained and employed in the remediation of the same facilities. ${ }^{1}$ A longer-term benefit would also accrue if these workers, now trained and experienced, were used as an exportable labor force for employment in other remediation operations, including those conducted under Base Realignment and Closure, Defense Environmental Restoration Program, Installation Restoration Program), and other military and civilian programs. In short, the apparent problems of a shortage of trained explosive ordnance demolition specialists and high levels of unemployment near many sites to be remediated could, with planning and foresight, be substantially alleviated in the long term as well as the short term.

The Military Munitions Waste Working Group believes, therefore, that the proper approach to be taken in developing the labor force necessary to support the conduct of military munitions waste remediation nationwide is to train local labor pools in the new skills needed for munitions waste remediation, and to use the existing group of explosive ordnance demolition specialists as the nuclei of these labor forces. The explosive ordnance demolition specialists are a select group of individuals who have undergone extensive and ostly training in all aspects of munitions identification, han-

\footnotetext{
'The labor requineme'nt for a moderately large thensands of ac res) ancexploded ordnance remediation project amounts to approximately one man-week per acre, aberaged oner all the occupations involved. Thus a project of 5000 ar res will rectuire roughly 100 man-years of habor for rompletion.
} 
dling, and disposal. ${ }^{2}$ Their knowledge and experience must be optimally used, both in the leadership and the direction of munitions waste remediation operations, and in the performance of those specific tasks for which they are uniquely qualified.

Certain activities in munitions waste remediation require specialized explosive ordnance demolition training and experience, but many tasks do not require this specialized expertise. The skills necessary for performing these tasks can be taught, given the development of appropriate courses of study, preparation of teaching materials, and definition of standards and requirements for skill certification. By building and employing remediation teams comprised of an optimal mix of explosive ordnance demolition specialists and trained local labor, the Military Munitions Waste Working Group believes that the present labor shortfall could be reversed and that remediation operations could proceed on a wider scale than would otherwise be possible.

An example of this approach involves remediation of sites contaminated with buried unexploded ordnance. The three following principal tasks are required:

- Identifying and marking surface unexploded ordnance items ar 1 determining and marking suspected locat ions of buried unexploded ordnance items,

- Accessing and recovering the items found at these locations, and

- Disposing of recovered munitions.

The first task, detecting and locating suspected unexploded ordnance items, does not require the skills of an explosive ordnance demolition specialist. This task, vitally important in a clearance operation, is presently best performed by individuals walking over terrain equipped with magnetometers, electromagnetic induction detectors, or other detection and location instruments. Missed detection of hazardous objects increases the post-clearance risk associated with the site. "False alarms," or detections of harmless objects or objects that are in fact not present. drive up the clearance time and cost because all suspected targets must be excavated. The second task, access and recovery of buried unexploded ordnance items must be directed by a trained explosive ordnance demolition technician, but much of this task can be performed by nonspecialist supporting personnel. The specific expertise of the explosive ordnance demolition specialist is required primarily in the third task, deactivation and safe disposal of the recovered munitions.

\footnotetext{
'Explosive ordnance demolition training is focused primarily on ordnance disposal under wartime conditions rather than on environmental remediation per se. Thus the most critical individuals in the explosive ordnance demolition labor pool will be those who have both leadership skills and an thil experience in munitions waste remediation.
} 
A training course in locator operation and use could be developed and taught at community colleges to students with basic knowledge of elementary physics. Such a course, with a possible duration of two weeks, would comprise both classroom and field work. The classroom portion might involve lectures based on viewgraph transparencies and computer simulations (the "textbook" would be the collection of annotated viewgraphs), using modern multimedia computer techniques of the fundamental physics on which a locator operation is based. These computer demonstrations might include, for example, simulations of the modifications of Earth's magneti: field in the neighborhood of a ferrous bomb-shaped object - the physical basis for the operation of the magnetometer, the most commonly used detection instrument in unexploded ordnance survey work.

Field exercises, planned and integrated with the classroom work, might begin with simple demonstrations and experiments (an example would be using a compass to investigate the magnetic field around an exposed ferrous object). Experiments might continue using detection equipment operating around an exposed test object supported above the ground and culminate in actual searches for buried objects. Safe handling procedures could be emphasized, and the students could be introduced to common munitions and the special hazards associated with them.

Test materials and predefined success levels could be used to certify the students' capabilities in the location of buried unexploded ordnance items. Such certification standards should be developed by the Corps of Engineers, the Naval Explosive Ordnance Demolition Technology Center, and the Army Environmental Center.

In a similar fashion, specialized training courses could be developed for other skills needed in munitions waste remediation that do not require explosive ordnance demolition-specific expertise. For example, other courses could provide training for operations in environments contaminated by chemical waste, and in the use of more sophisticated suites of detection and location sensors. Such courses could be developed by technical experts working jointly with explosive ordnance demolition specialists and taught at local schools and community colleges. Using appropriate computer techniques, field demonstrations, experiments, and knowledgeable and experienced instructors, the courses could contribute significantly to the development of skilled labor pools, the conduct of remediation operations, and the economic betterment of communities - particularly those affected by base closures.

A program is currently being proposed by Lawrence Livermore National Laboratory to use Hawaiian environmental projects, such as the remediation of the Island of Kaho'olawe, as a basis for developing environmental knowledge and skills among the Native Hawailan population. This program, which would include general scientific and specialized training courses as well as field work to reinforce classroom concepts, is being developed by Lawrence Livermore National Laboratory with participation from local gov- 
ernment and Native Hawalian organizations. The Lawrence Livermore National Laboratory program is consistent with the two goals that have been discussed here: assisting in the remediation itself and developing a skill base within the local population. This program merits further attention.

The Western Governors' Association could play an important role in developing a coherent education and training policy that is directed toward the solution of military munitions waste remediation problems and addresses short- and long-term critical economic issues. By bringing together representatives of affected communities, responsible Federal agencies, the technical expert community, the community of explosive ordnance demolition specialists, and local educational institutions, and by acting as the focal point for the effort in the Western United States, the Western Governors' Association could take an active leadership role in education and training policy development. This is an appropriate activity for the association, and the Military Munitions Waste Working Group recommends that it be vigorously pursued.

On May 14 and 15, 1993, the DOIT Committee's Ad Hoc General Criteria Working Group met to set up guidelines for the four DOIT Committee Waste Area Working Groups. The Military Munitions Waste Working Group reviewed the criteria and drafted further additions that were more specific to the working group. As a result of these meetings, a combination of the criteria from both the Ad Hoc General Criteria Group and the additional Military Munitions Waste Working Group criteria have been combined into a final list of criteria for the working group. The following is a list of the combined demonstration criteria used to identify the Military Munitions Waste Working Group's selected sites. The list is divided into four categories: site selection criteria, technology selection criteria, evaluation critc. ria, and contractor selection criteria.

\subsection{CRITERIA USED TO IDENTIFY AND SCREEN POTENTIAL DEMONSTRATION PROJECTS}

\subsection{Site-Selection Criteria}

- Federal site - preferably in the west.

- Current and future jurisdiction over the lands in the site.

- Not a security (classified) site. 
- Any ongoing litigation or administrative action related to the site will not likely delay or prevent successful completion of a demonstration.

- Current and future land use of the lands in the site.

- Risk to the general public from energetics waste.

- The site is representative of energetics problems at government facilities and other sites.

- Public awareness concern about the problems at the proposed demonstration site and remediation of the site are supported by Federal, State, and local governments; responsible parties; and other stakeholders.

- Economic benefit to society from remediation of the site.

- Typical or reasonably challenging environmental situation for demonstration of the technology with respect to topography, vegetation cover, climate, threatened/endangered species, etc.

- The degree to which the following conditions exist at the site:

- The site is characterized by a range of energetics waste disposal problems that may necessitate a suite of technologies, including those appropriate to preclude catastrophic failure.

- A significant variety and volume of contamination are present to both challenge the technology and to facilitate a statistical evaluation of the effectiveness of the technology.

- There is adequate access to the contamination.

- There is an ability of selected demonstration sites to account for site-to-site variables and establish the range of effectiveness and cost for a technology.

- The extent to which the required utilities and infrastructure (both human and physical) are avallable.

- Location is adequately isolated to limit human and environmental risk from deployment of the technologies. 


\subsection{Technology Selection Criteria}

- The technology, within a system's context, is potentially better, faster, or safer compared to conventional technology (some apply to treatment, others to characterization and monitoring, and some apply to both) including but not limited to:

- Shorter timeframe,

- Lower cost,

- Lower detection limits for characterization technology.

- Lower cost per unit of weight/volume.

- Lower offsite migration potential.

- Lower emissions,

- No or fewer adverse byproducts.

- Improved permanence of remedy.

- Reduced residuals. disposal problems,

- Reduced contaminants' concentrations in treated media,

- Increased understanding of the range of operating parameters,

- Improved reliability, and

- Broad applicability.

- The proposed technology has the potential for successful demonstration in relatively short timeframe (i.e., years not decades).

- The proposed technology has the potential for timely commercialization.

- Proposed demonstration technology is supported by Federal, State, and local governments, responsible parties, the broader community, and all stakeholders.

- The technology has expected outcomes that are measurable and clearly understood.

- The regulatory process for the technology will not preclude a successful demonstration.

- The technology demonstration has quality assurance/quality controls built in.

- The technology demonstration includes comparison of multiple technologies or suites of technology. possibly including "test-offs/competitions." 


\subsection{Evaluation Criteria}

\subsubsection{Technical}

- Did the technology achieve established test objectives?

- Did the demonstration project contribute to a better understanding of the usefulness of the technology?

- Were the test protocols adequate?

- Did the demonstration advance the technology?

- Are demonstrations broadly applicable to other sites?

- Is test data available?

\subsubsection{Process}

- Were stakeholders appropriately involved? Did or could they play a significant role in light of the technical and complex issues involving the application of innovative technology?

- Did the demonstration contribute to the resolution of commercialization issues for the technology?

- Did the demonstration contribute to the improvement of the process of technology development and deployment?

- Did the demonstration provide adequate information for user adoption or adaption?

- Did the dernonstration further the business objectives of the private partners in the project?

- Did the project sponsors understand and address adequately the stakeholder concerns?

\subsection{Contractor Selection Criteria}

- Ability of the contractor to do the work

- Proven track record, and

- Available resources.

- Partnerships are encouraged. 


\subsection{LIST OF POTENTIAL CANDIDATE DEMONSTRATION PROJECTS FOR THE DOIT COMMITTEE DECISION/ RECOMMENDATION}

Hundreds of candidate sites are avallable to select from for demonstrations. The U.S. Army Corps of Engineers lists as many as 900 formerly used Defense sites that are contaminated with ordnance explosive waste. Others estimate that there are more than 1,000 sites. Additionally, military base closures, as well as active facilities, provide another ready source of demonstration sites that need remediation for current activities to continue safely.

The technological innovations in the field of ordnance explosive waste detection, identification, and remediation appear to be more evolutionary than revolutionary. The primary issue is the ability of the technology and operators to perform as advertised. Therefore, stringent test situations need to be established to evaluate the effectiveness and efficiency of the existing systems and evolutionary improvements to these systems. These results must be repeatable 10 be accepted by the scientific and stakeholder communities.

We have identified the need for two test/demonstration site categories:

- Controlled test sites are designed and constructed to replicate actual field situations with all parameters precisely known, using inert munitions and munitions waste. These sites will be used to accurately evaluate the test results from technologies in research and development.

- Uncontrolled demonstration sites are sites with actual contamination where most, but probably not all, of the contaminant characteristics are known. Evaluating the effectiveness and efficiency of the demonstrated technologies will be less accurate. These sites provide a variety of environmental settings in which to demonstrate technologies which have already been proven under controlled test site environmental conditions. These sites shall have explosives safety controls established to protect authorized observers during the conduct of the demonstrations.

Both site categories are suitable for demonstration of the DOIT ( le:all up approaches and methodologies, including stakeholder involvement.

Documentation of the tests and demonstrations at both the controlled and uncontrolled sites will provide credentials for the 
technology and the company. This documentation will provide the information necessary for a site manager to proceed with confidence when contractirig for innovative technologies to remediate a site.

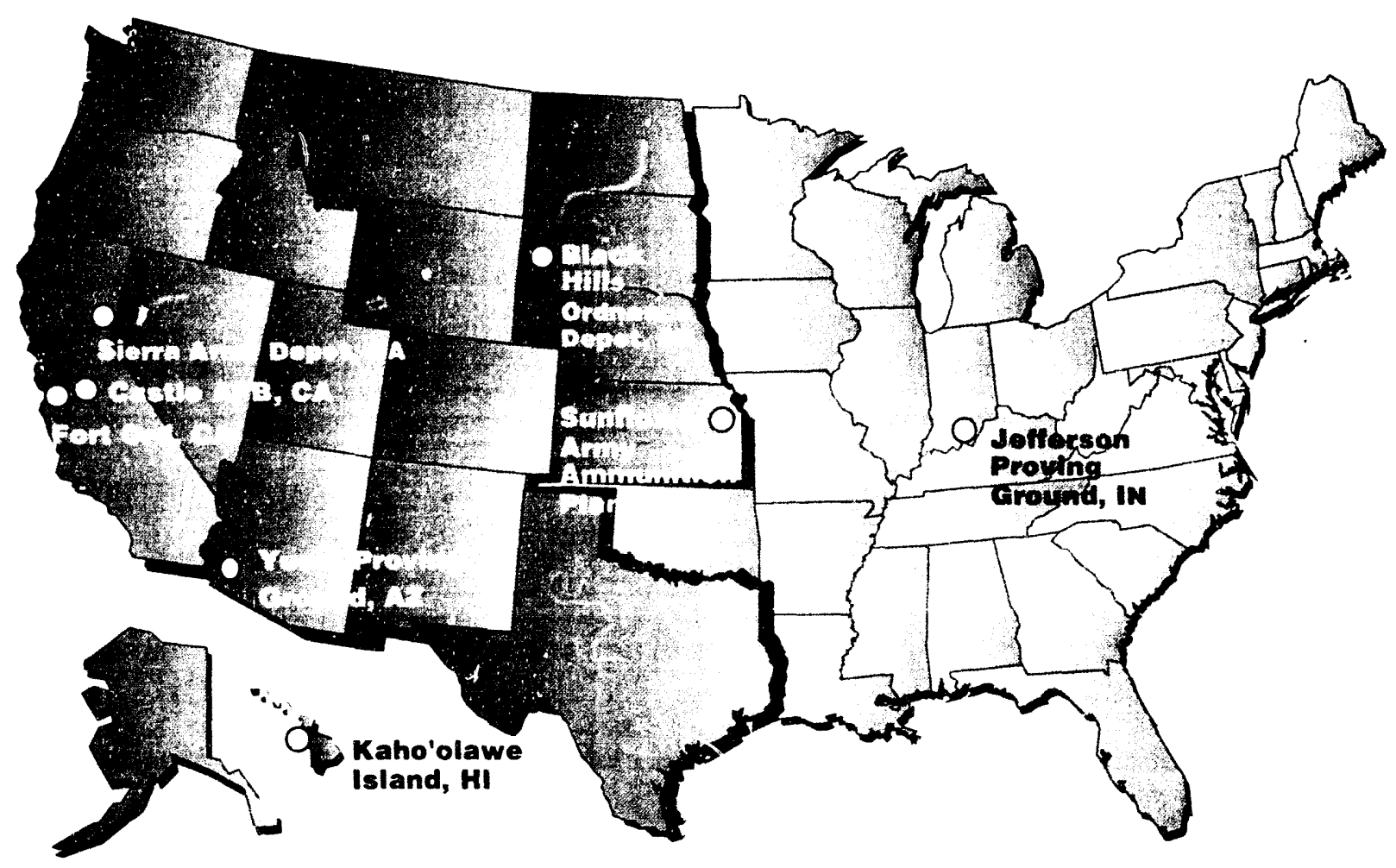

Using the knowledge of the members of the Military Munitions Waste Working Group and the screening criteria listed earlier, an initial set of eight demonstration sites has been identified for further consideration. The sites have been identified as appropriate to demonstrate innovative technologies under both controlled and uncontrolled field situations over a variety of characterization and remediation problems and in a range of environmental settings. The next step is to contact service/site officials, where this has not already been done to determine the feasibility and parameters of a demonstration at those site. Additional sites will be identified until a full suite of demonstration sites has been identified that cover the full range of ordnance explosive waste problems and site environmental characteristics.

The most promising source of demonstration sites found was the Site Candidates list for energetics proposals that was developed in support of the National Department of Defense Environmental Technology Sites Program for Energetics (Appendix A). The Site Candidates list includes sites from the Model Base Closure Program. the Expedited Closure Program, the CERCLA National
Military Munitions Waste Horking Grontpis Le'mified Sites for Consuderanion an DonT Demonstranem Sines 
Priority List, and Department of Energy technology test sites. The Department of Defense technology sites program is intended to establish a "national test bed" suite of sites for demonstrating and evaluating technologies. There would also be field condition demonstrations at actual cleanup sites. As this program is similar to the DOIT Committee effort, the Military Munitions Waste Working Group strongly endorses this concept. Most, but not necessarily all, potential DOIT Committee demonstration sites identified by the Military Munitions Waste Working Group will come from the Site Candidates list.

The following eight sites have been identified for consideration as DOIT Committee ordnance explosive waste demonstrations:

- Jefferson Proving Ground. Indiana: FY 1995 Army base closure. Research and development technology testing/ demonstration for subsurface unexploded ordnance detection, identification, and remediation in a controlled test environment.

- Yuma Proving Ground, Arizona: Active Army facility. Research and development and applied technology testing/demonstration for surface unexploded ordnance detection. identification. and remediation in both controlled and uncontrolled test environments. This would also be a DOIT Committee process demonstration sitc.

- Fort Ord, California: FY 1995 Army base closure. Range and maneuver area. Applied technology demonstration for contaminated media. surface and subsurface unexploded ordnance detection; identification and remediation in an uncontrolled test environment. This would also be a DOIT Committee process demonstration site.

- Kaho'olawe Island, Hawaii: Navy formerly used Defense site. Applied technology demonstration for contaminated media, surface and subsurface, and underwater unexploded ordnance detection, identification, and remediation in an uncontrolled test environment. Extremely environmentally challenging. This would also be a DOIT Committee process demonstration site.

- Castle Air Force Base, California: FY 1995 Air Force base closure. Open burn/open detonation area. Research and development and applied technology testing/demonstration for contaminated media and subsurface unexploded ordnance detection, identification, and remediation in an uncontrolled test environment. This would also be a DOIT Committee process demonstration site. 
- Sierra Army Depot, California: Active Army demilitarization facility. Research and development and applied technology testing/demonstration for contaminated media, demilitarization processes, and subsurface and underwater unexploded ordnance detection, identification, and remediation in both controlled and uncontrolled test environments. This would also be a DOIT Committee process demonstration site.

- Black Hills Ordnance Depot, South Dakota: Army formerly used Defense site. Applied technology demonstration for surface and subsurface unexploded ordnance detection, identification, and remediation. This would also be a DOIT Committee process demonstration site.

- Sunflower Army Ammunition Plant, Kansas: Partially active and partially closed Army ammunition manufacturing facility. Research and development and applied technology testing/demonstration for contaminated media. This would also be a DOIT Committee process demonstration site. Possible future demilitarization site for missiles is a research and development opportunity for missile fuels technology.

- Delta Range, Colorado, and Davis Range, Alaska: These two formerly used Defense sites, previously identified in the Military Munitions Waste Working Group report of May 14 and 15, 1993, have been dropped from consideration.

\subsection{Jefferson Proving Ground, Indiana}

Jefferson Proving Ground is scheduled for closure by the last quarter of FY 1995. The facility's mission of evaluating ammunition and components produced for the Army is to be transferred to the Yuma Proving Ground in Arizona.

Jefferson Proving Ground has been used to test ammunition since May 1941. The Army estimates that 23 million munitions items have been tested at the Jefferson Proving Ground during this half century of operations and that as many as 1.5 million unexploded ordnance items may still exist within the boundaries of the facility. Additionally, there are areas contaminated by explosives, hazardous chemicais, and depleted uranium. Currently, reuse options are being identified and considered for Jefferson Proving Ground. 
In FY 1993, Congress appropriated funds to perform an Unexploded Ordnance Technology Demonstration at Jefferson Proving Ground in FY 1994. The Army Environmental Center was tasked to create a controlled test site at Jefferson Proving Ground and to assess the state-of-the-art in unexploded ordnance detection, identification, and remediation technology by conducting multiple demonstrations and evaluating the results. This largescale demonstration project will allow for a thorough investigation of unexploded ordnance technologies available within the private sector.

The DOIT Committee will be kept abreast of this ongoing effort and will receive test results and the final report.

\subsubsection{Purpose/Goals of Demonstration}

This project is designed to assess the state-of-the-art in unexploded ordnance detection, identification, and remediation technology by conducting multiple demonstrations and evaluating results. Both research and development (prototype) systems and advanced technology systems will be included in this demonstration.

\subsubsection{Description of Project}

The demonstration site will contain two areas 140 acres and 80 acres), each with inert ordnance and other debris. The 40-acre area will be used to test and demonstrate man portable and surface-towed systems. The 80 -acre area will be used to demonstrate airborne systems. The inert ordnance and debris will be serialized and accurately positioned for reacquisition. After system demonstrations, reliability and accuracy estimates will be generated. A comprehensive report will be written describing the technologies tested, results, and a comparison of technologies.

\subsubsection{Organization/Management}

This demonstration program is managed by the Army Environmental Center, Aberdeen Proving Ground, Maryland. Ms. Kelly Rigano, Program Manager at the Army Environmental Center, is a member of the Military Munitions Waste Working Group.

The Army Environmental Center has tasked the Naval Explosives Ordnance Disposal Technology Center, Indian Head, Maryland, to execute this program. The Naval Explosives Ordnance Disposal Technology Center Project Manager is Mr. Jerry Snyder.

\subsubsection{Timing/Schedule of Activities}

- Solicitation for and selection of technology demonstrators

$$
\begin{array}{r}
10 / 93-1 / 94 \\
10 / 93-4 / 94 \\
5 / 95-10 / 94 \\
7 / 94-10 / 94
\end{array}
$$

- Preparation of the demonstration site

- Technology demonstrations 


\subsubsection{Estimated Costs/Funding Status}

In FY 1993, \$5 million was appropriated for the Jefferson Proving Ground demonstration effort.

\subsubsection{Selection Criteria}

Site Criteria

- Jurisdiction: Department of the Army

- Current and Future Land Use: Jefferson Proving Ground can be broken into two areas: 50,950 acres north of the firing line and 4,315 acres south of the firing line. Environmental cleanup and reuse options are currently being considered for the area south of the firing line. The northern area cleanup and reuse issue is deferred until the Jefferson Proving Ground mission is terminated.

- Potential Risk: Risk is currently low since access is restricted to authorized personnel. The demonstration area will be verified as clean (safe) prior to placement of inert ordnance and demonstrators are permitted into the areas.

- Representative Site: Jefferson Proving Ground is representative of a large number of impact and training ranges around the world. The demonstration site will lay out ordnance at depths, locations, and orientations that ordnance is typically found at (when that ordnance is found on impact ranges or battlefields).

- Current Public Awareness and Involvement: The Jefferson Proving Ground Regional Development Board is a community group that addresses reuse issues and protects the interests of the community. The planned unexploded ordnance technology demonstration has not yet been presented to this board or any other community group. Contact with potential stakeholders is currently made through the Jefferson Proving Ground Public Information Office.

- Economic Benefit to Society from Remediation of the Site: The goal of the unexploded ordnance demonstration is to identify state-of-the-art detection and remediation technology. This technology can later be considered for further "real-life" demonstrations or for remediation type work.

- Site Conditions:

- Range of Contaminant Values: The two demonstration areas will contain a wide variety of inert ordnance and debris. The inert ordnance will be accurately positioned at varying depths, locations, and orientations. The ordnance area layout will be based upon data from unexploded ordnance contaminated sites.

- Contamination Characteristics: Only subsurface inert ordnance will be emplaced on each site. 
- Site-to-site Variables: Soil type, moisture content, topography, and vegetative cover vary from site-tosite.

- Environmental Variables: Jefferson Proving Ground is situated within the southern fringe of the Central Lowland physiographic province, an area characterized mostly by low rolling landscape and nearly level plains. The geology is that of glacial till overlying bedrock, and consists of limestones and dolomite interbedded with shales. Soils at Jefferson Proving Ground have developed from glacially derived parent materials.

- Access: The demonstration sites will be located in the east/northeast section of Jefferson Proving Ground (north of the firing line). Access roads are of high quality.

- Infrastructure: The existing Jefferson Proving Ground infrastructure will probably be sufficient to accommodate the test facility.

- Isolated Location: Not a factor.

\section{Technology Criteria}

The Technical Demonstration Solicitation is currently (October 1993) being advertised in the Commerce Business Daily. Solicitation letters have also been sent directly to companies known to be performing work in this area. Specific demonstrator selection criteria are currently being generated.

- Demonstration Period: May through October 1994.

- Potential for Timely Commercialization: Commercialization is not a specific goal of this demonstration; however, the demonstration should assist the most promising technologies move toward commercialization.

- Support for Technology: Funding will be provided to those companies chosen to perform unexploded ordnance demonstrations at Jefferson Proving Ground. All viable technologies will be considered for demonstration.

- Part of a Technology "Test-off or Competition:" The goal of the unexploded ordnance demonstration is to identify state-of-the-art detection and remediation technology. Reliability and accuracy estimates will be generated for each system and comparisons between systems will be made.

- $\quad$ Regulatory Process Issues: None. 
- Quality Assurance/Quality Controls: Demonstrator test data will be compared to actual data. Reliability and accuracy estimated will be generated.

- Measurable Outcomes: State-of-the-art unexploded ordnance detection and remediation technologies will be identified.

\section{Evaluation Criteria}

Demonstrator test data will be compared to actual data. Reliability and accuracy estimates will be generated.

\section{Contractor Criteria}

Not applicable.

\subsection{Yuma Proving Ground, Arizona}

The Yuma Proving Ground is a portion of the Department of Defense's Test and Evaluation Range facilities that comprise over 50 percent of the Department of Defense's land holdings. To keep these facilities operating at full capability, a clean-as-you-use range cleanup capability must exist. The focus of this research and development and applied technology effort is the location, identification. and remediation of surface unexploded ordnance. The DOIT Committee has been invited to participate as full partners with Yuma Proving Ground in its effort to develop and field range cleanup technologies.

\subsubsection{Purpose/Goals of Demonstration}

Develop, test, and evaluate technologies for range cleanup of surface unexploded ordnance.

\subsubsection{Description of Project}

Using a combination of small, controlled test sites and actual range facilities, a program will be developed to test surface munitions detection, mapping, and remediation technologies that are capable of operating on a continuing basis over large areas. Emphasis will be placed on airborne platforms for safety reasons. This site also has potential for future demonstrations relating to remediation of depleted uranium munitions waste.

\subsubsection{Organization/Management}

This program will be operated by the Advanced Technology Office of the Yuma Proving Ground. The Program Manager is Mr. Andy Hooper, who is a member of the Military Munitions Waste Working Group. 


\subsubsection{Timing/Schedule of Activities}

Initial planning is underway. At the September 30, 1993, meeting of the Military Munitions Waste Working Group, it was reported that a detection vehicle/technology has been recently declassified. The working group will work to establish contacts between the owners of this technology and the Yuma Proving Ground for a possible demonstration/test within the next few months.

\subsubsection{Estimated Costs/Funding Status}

This will be an continuing program. Funding has been made available through the Test and Evaluation Program starting in FY 1993.

\subsubsection{Selection Criteria}

\section{Site Criteria}

- Jurisdiction: Department of the Army

- Current and Future Land Use: The Yuma Proving Ground is an active test range that is currently engaged in testing current and future U.S. Army munitions and weapons systems. Yuma Proving Ground has been in use since the early 1940's. There are no competing land uses. Continued use of Yuma Proving Ground as a test range in an increasingly difficult regulatory environment will depend upon Yuma Proving Ground's ability to clean the existing test ranges and keep them clean. Total installation: 889,000 acres; contaminated range areas: in excess of 250,000 acres.

- Potential Risk: There is no offsite risk. There are significant risks to unauthorized persons who may inadvertently cross the range areas. There is an extreme risk to personnel engaged in cleanup of modern munitions.

- Representative Site: This site is representative of a number of test and evaluation ranges in desert environments worldwide, as well as battlefield situations that left unexploded ordnance on the surface.

- Current Public Awareness and Involvement: Awareness of the need for cleanup resides primarily within the military and the State of Arizona environmental office. A stakeholder effort would heighten public awareness and gain support for continuing efforts at cleanup, including technologies that possibly could not be tested at less remote locations.

- Economic Benefit to Society from Demonstrations at the Site: Improved cleanup technologies would allow continued use of the existing ranges, thereby minimizing 
additional commitments of land resources to contamination as range facilities. The developed technologies also would be useful worldwide under similar environmental conditions to clear ranges and battlefields.

- Site Conditions:

- Range of Contaminant Values: The ranges are contaminated with a wide variety of Army munitions. Some have been in use since the early 1940's, and some are being tested for future use. These include depleted uranium and modern submunitions.

- Contamination Characteristics: Munitions waste is primarily unexploded ordnance and scrap from detonations on the surface and in the neisi subsurface. Cleanup will concentrate on surface munitions. Munitions below the surface will be left in place.

- Site-to-site Variables: This site is typical of range areas in a desert environment. Concentrations may be higher than at many ranges, and the occurrence of the more lethal modern submunitions will be higher.

- Environmental Variables: The environment is Sonoran Desert with sand, and rock, sparse vegetation, and a deep water table. Topography is rolling with arroyos, which makes it difficult for ground vehicles to traverse in a set grid pattern.

- Access: Access is provided by the existing Yuma Proving Ground road network.

- Infrastructure: The existing Yuma Proving Ground infrastructure is capable of supporting demonstrations of technologies associated with all forms of detection and remediation of unexploded ordnance.

- Isolated Location: The Yuma Proving Ground provides extrcmely remote test areas where essentially any technology can be tested safely. Attempts to test some of the more exotic technologies are more likely to meet resistance for environmental reasons than for safety reasons.

\section{Technology Criteria}

The facilities for demonstrations will be available for a wide variety of technologies and contractors. Some of the technologies to be tested will require millimeter accuracies using laser trackers. These tracking systems are available at the Yuma Proving Ground.

- Test Date: Test design could begin immediately with demonstrations to take place upon completion and acreptance of the test design. 
- Potential for Timely Commercialization: There is a current demand for these technologies for cleanup of existing ranges, formerly used Defense sites, and battleflelds on a worldwide basis. Examples where the technologies could be used are U.S. test ranges, formerly used Defense sites, Afghanistan, the Middle East, Pacific islands, Russia, and Bosnia.

- Support for Technology: The development for this technology is supported by the Department of Defense and other Federal land managing agencies.

- Part of a Technology "Test-off or Competition:" While this is not a test-off, a result of these demonstrations will be an evaluation of the effectiveness of the technologies being tested. These can be compared when determining which technology to apply to a specific cleanup problem elsewhere.

- Regulatory Process Issues: Arizona environmental regulators may be asked to waive certain requirements for the sake of knowledge gained from a certain test protocol. Therefore, it is essential that all appropriate Arizona offices are part of the stakeholders group.

- Quality Assurance/Quality Controls: Quality will be covered in the test protocols.

- Measurable Outcomes: Measurable outcomes will be covered in the test protocols.

\section{Evaluation Criteria}

Evaluation criteria will be developed by the Yuma Proving Ground with input from the local stakeholders group.

\section{Contractor Criteria}

Contractor criteria will be developed by the Yuma Proving Ground with input from the local stakeholders group.

\subsection{Fort Ord, California}

Fort Ord is scheduled for base closure action under the second round of Base Realignment and Closure (BRAC II). Lands will be transferred out of Department of Defense control into public use. Only installation areas that cleanup technology is able to render safe will be available for planned reuse.

\subsubsection{Purpose/Goals of Demonstration}

This is primarily a demonstration of the stakeholder process and how it can be used during a base closure where there is a range area with munitions waste. This site will also be used for applied 
technology demonstrations in an environment that is different from the environment at either Jefferson Proving Ground or Yuma Proving Ground.

\subsubsection{Description of Project}

The demonstration will focus on range and maneuver areas. The partnership methodology will be used to arrive at a balance among future land uses, technology capabilities, and funding avallability. The potential risk to users of the proposed end use of the lands is the controlling facto: for determining this balance. Innovative technology to be demonstrated will include munitions waste detection and fpar(ial) removal, both surface and subsurface over extensive acreage, and soils contaminant detection and remediation in the primary impact areas and where munitions stocks may have been buried. This is an environmentally challenging clemonstration location because of concern for the habltat of threatened and endangered species.

Contact will be made with the site manager and the existing local base reuse committee known as the Fort Ord Task Force. By working with them, a new stakeholders group would be organized, if appropriate, to address the munitions waste issues. This group would undertake an analysis of the potential risk, proposed end use of the lands. and technologies and funding available.

The end product will be the cleanup of the range and maneuver areas sufficient to allow the proposed future use as determined by the Fort Ord Task Force. During this process, demonstrations of detection, identification, and remediation technologies for unexploded ordnance and contaminated media would be demonstrated for their effectiveness in this environmental setting of soils, terrain, vegetation, and threatened and endangered species habitat.

\subsubsection{Organization/Management}

This demonstration would be conducted under the existing base closure organizational structure.

\subsubsection{Timing/Schedule of Activities}

Activities could begin as soon as the site manager accepts the designation as a DOIT Committee demonstration site. Initial activity would be the establishment of the stakeholders group and potential risk analysis.

\subsubsection{Estimated Costs/Funding Status}

The funding for this effort would come from the base closure fund, Defense Environmental Restoration Program funding, and possibly Strategic Environmental Research and Development Program funds. There is no estimate of the cost. Since cleanup has to be accomplished anyway, any additional costs associated with a demonstration of methodology would be minimal. 


\subsubsection{Selection Criteria}

\section{Site Criteria}

- Jurisdiction: Department of the Army.

- Current and Future Land Use: The installation has been used as an infantry division base and training area since 1917. Current maneuver areas will most likely contain small arms blank ammunition and pyrotechnic grenades and flares. The maneuver areas may also have former but currently unknown impact or disposal areas. The range area will have munitions waste, including unexploded ordnance, ranging from small armsi ammunition to 8-inch howitzer shells. The installation includes approximately 20,000 undeveloped acres: a maneuver area of approximately 12,000 acres and an 8,000-acre range area.

- The Base Realignment and Closure environmental statement and the Fort Ord Task Force are considering a variety of uses for the installation. Most of the installation will leave Department of Defense jurisdiction. Developed portions of the installation (approximately 8.000 acres) will be transferred to a variety of communities and users. The shore line will likely become part of the Stall. Park System. The majority of the maneuver and range areas will likely remain as open space/recreation lands under the jurisdiction of another Federal agency (probably the Bureau of Land Management) or a State agency.

- Potential Risk: The risk from unexploded ordnance, both surface and subsurface, in the range area is very high. The risk from surface unexploded ordnance in the maneuver area will remain moderate until a surface sweep can be conducted; then it will be low. The risk from contaminated media in the range area is thought to be low.

- Representative Site: The range and maneuver areas are fairly typical of other Army installations that may be closing. These characteristics are replicated at other installations around the world.

- Current Public Awareness and Involvement: Local citizens and governments are deeply involved with the future use of this installation. Public safety when using the land after the base closes is a very important issue. Environmental interest groups are concerned about retention of the maritime chaparral ecosystem.

- Economic Benefit to Society from Remediation of the Site: Reuse of these lands will affect the local commmum ties and the health of the threatened and endangered species habitat. 
- Site Conditions:

- Range of Contaminant Values: The range of contaminants and the variability of their density over a large area are significant. Additionally, there will be contaminated media in the more heavily used range impact areas.

- Contamination Characteristics: Small arms blank munitions and pyrotechnics are thought to be in the maneuver area. The range area contains all calibers of munitions from small arms through 8-inch howitzer shells and possibly some bombs.

- Site-to-site Variables: The munitions values and characteristics are fairly representative of Army installations.

- Environmental Variables: Rolling hills with maritime chaparral habitat. State- and Federal-listed threatened and endangered species are located on the installation. The presence of threatened and endangered species is fairly representative; however, the habitat is not representative of most installations.

- Access: Excellent.

- Infrastructure: The existing infrastructure should be capable of supporting any demonstrations as well as the cleanup effort.

- Isolated Location: The installation is fairly small and has surrounding communities and farms. There may be technology limitations because of the relative closeness of human presence.

\section{Technology Criteria}

- $\quad$ Test Date: Technology demonstrations could begin as soon as the stakeholders group is formed and the potential risk versus end use of the land is analyzed and understood.

- Potential for Timely Commercialization: Technology demonstrations will be of applied technology that has been proven in prior commercial use or has been used at Jefferson Proving Ground or Yuma Proving Ground. If the technology is viable in the environmental setting of Fort Ord, then it could be contracted to do cleanup work there or at similar environmental settings.

- $\quad$ Support for Technology: Support for the technology would be determined by the stakeholders group and the effectiveness of the technology in the environmental setting.

- Part of a Technology "Test-off or Competition:" This is not part of a test-off or competition. 
- Regulatory Process Issues: To be determined.

- Quality Assurance/Quality Controls: To be determined.

- Measurable Outcomes: Technology enhancements that will satisfy the cleanup requirements of the stakeholder group and that are cheaper, better, safer, or faster than existing technology.

Evaluation Criteria

- Technical

- Achieve Test Objective: To field demonstrate technologies that are cheaper, better, safer, or faster.

- Add to Understanding of Tested Technology: This site would expand test data for existing technology to a different environment.

- Demonstration Protocols Adequate: Demonstration protocols will be translated into future contract standards; therefore, were they adequate to achieve the desired result?

- Demonstration Advance Technology: Did the demonstration advance the understanding or development of the technology being demonstrated?

- Applicable to Other Sites: Are the results applicable to other sites with the same contaminant characteristics and environmental setting?

- $\quad$ Process

- Stakeholder Involvement: Were the appropriate stakeholders involved?

- Stakeholder Concerns Adequately Addressed: Did the stakeholders influence the design of technology demonstrations and eventual cleanup effort?

- Contribute to Commercialization: Where there any significant technology advancements made that could be commercialized?

- Contribute to Technology Development and Deployment: Were advancements made in development and deployment of technology?

- Provide Information for User Adoption/Adaption: Were the results of demonstrations made public?

- Further Business Objectives of Partners: Did the demonstration support the business objectives of the private sector partners? 


\section{Contractor Criteria}

- Proven Track Recor': The demonstration contractor should have a proven track record at other cleanup sites or the Jefferson Proving Ground or Yuma Proving Ground test sites.

- Available Resources: The contractor should have sufficient resources to clear a designated portion of the maneuver area and/or a portion of the range area.

\subsection{Kaho'olawe Island, HI}

The cleanup effort on Kaho'olawe Island is strongly supported by the Governor, congressional delegation. and peoples of Hawaii. Legislative language to make up to $\$ 400$ million over 10 years available for cleanup and conversion of the island into a State park recently passed Congress in the 1994 Defense Appropriations Act.

\subsubsection{Purpose/Goals of Demonstration}

This is primarily a demonstration of the stakeholder process and how it can be used during the cleanup of a range where the lands are 10 become a State park with public access. This site can also provide a test bed for research and development and applied technology demonstrations in a very challenging enviromment.

\subsubsection{Description of Project}

The cleanup and conveyance of this isiand to the State of Hawaii has been the subject of both Executive Order and legislation. This is a high profile cleanup issue, with congressional and gubematorial support. The island is sufficiently isolated so that constraints on the use of innovative technologies would be limited by only environmental and cultural (religious, archeological, and historicall concerns. The situation on Kaho olawe is well known, and a clearance plan has been prepared.

The partnership methodology will be used to ensure sensitivity to sites of cultural and religious significance on the island and to ensure that the appropriate level of cleanup for the end use of the lands is achieved. Innorative technologies to be demonstrated include: munitions waste detection and removal from the surface, subsurface, and underwater to depths required to accommodate intended land uses, over a large area (29.000 land acres plus underwater areas): and survey and cleanup of soil contaminants (explosive compounds and their decomposition products) in impact areas and where mumi tions stocks may have been buried. (Note. however. that no eridence exists that such stocks have been so disposed on Kahoolawe). The island is composed of a variety of terrain and, in some cases. magnetically active soils that will challenge the demonstration. 


\subsubsection{Organization/Management}

The demonstrations would be conducted under the current site manager with a stakeholders group, including the currently involved stakeholders and others as appropriate.

\subsubsection{Timing/Schedule of Activities}

A cleanup plan has been completed. Start of cleanup operations. including any demonstration projects, is dependent on congressional appropriations.

\subsubsection{Estimated Costs/Funding Status}

The 1994 Defense Department Appropriations Act contains $\$ 400$ million over 10 years for cleanup of the island and surrounding waters and conversion to a State park. In FY 1994, \$60 million is provided for cleanup. A portion of this funding may be available for the unexploded ordnance and contaminated media demonstrations.

\subsubsection{Selection Criteria}

\section{Site Criteria}

- Jurisdiction: Department of the Navy.

- Current and Future Land Use: The island has been a Navy ship, aerial gunnery, and bombing range since the 1930's. Some ground maneuvers have also taken place. Munitions waste includes everything from small arms munitions through 2.000-pound bombs and 16-inch naval gun shells. There has been no known use of chemical munitions.

- The island will become a State park for the protection of religious, archeological, and historically significant sites.

- Potential Risk: There is a significant risk to future users of the State park from surface munitions. Therefore. a detailed cleanup is needed. Subsurface remediation will be needed in areas of planned construction.

- Representative Site: This site represents some of the extremes in environmental settings that might be encountered during a cleanup effort. While this may be a singular U.S. site, there are similar sites in other parts of the world.

- Current Public Awareness and Involvement: The Protect Kaho olawe 'Ohana (family) is a broadly based, though predominantly Native Hawaian, group that has been active for many years in advocating the return of the 
island to the State of Hawaii, the remediation of its ordnance contamination, and its future restoration and preservation. The Protect Kaho'olawe 'Ohana must be considered as an important stakeholder in military munitions waste demonstration projects on Kaho'olawe.

- Hawaii's congressional delegation, the Governor, other State officials, and the general public (who will make use of the educational and recreational opportunities of the park) are also involved with the future status of the island.

- Economic Benefit to Society from Remediation of the Site: This is an important religious and cultural site for the people of Hawail. Cleanup of the island would restore a portion of their heritage.

- Site Conditions:

- Range of Contaminant Values: There is a wide range of munitions waste type and density, including contaminated media in the primary impact areas.

- Contamination Characteristics: In addition to surface, subsurface, and undeiwater unexploded ordnance. tons of scrap metal must be located and removed. Insitu treatment of contaminated soils in the impact areas is desired.

- Site-to-site Variables: Munitions wastes vary from heavy concentrations in the impact areas to widely dispersed individual rounds throughout the island. Extreme site variables range between relatively flat plateau areas to deep canyons, from sparse dry-side vegetation to semi-tropical vegetation, and across a variety of soil conditions.

- Environmental Variables: The site is a shield volcano with a variety of topographic features. Typical Hawaiian dry-side scrub vegetation with little vegetation at the higher elevations and some woodland.

- Access: Access is limited and controlled. There is a small airfield at the Navy base camp. Resupply by sea is possible under calm conditions.

- Infrastructure: A Navy base camp is located at the southwestern end of the island. Maui, about seven miles from the northwest end of Kaho olawe, is the nearest developed island.

- Isolated Location: Kaho'olawe is an island with the nearest occupied island, Maui, seven miles away. Most all technologies could be demonstrated if they are not destructive to the religious, archeological, and historical sites. 


\section{Technology Criteria}

This site has been identified to demonstrate advanced technology systems at an environmentally challenging location. Is the technology suitable for these environmental situations? Is the technology better, faster, safer, cheaper for cleanup in this environment?

- Test Date: To be determined.

- Potential for Timely Commercialization: Most technologies demonstrated here will already be commercialized or about to be commercialized.

- Support for Technology: Do the stakeholders support use of the technology to be demonstrated?

- Part of a Technology "Test-off or Competition:" This is not part of a test-off or competition.

- Regulatory Process Issues: To be determined.

- Quality Assurance/Quality Controls: To be determined by the site manager and local stakeholders.

- Measurable Outcomes: To be determined by the site manager and local stakeholders.

\section{Evaluation Criteria}

- Technical:

- Were test objectives achieved?

- Did the demonstration add to the understanding of capabilities of tested technology?

- Were the demonstration protocols adequate?

- Did the demonstration advance the state of the technology?

- Are the results from the demonstration applicable to other sites?

- Process

- Was there appropriate stakeholder involvement?

- Were stakeholder concerns adequately addressed?

- Did the demonstration contribute to commercialization of the technology?

- Did the demonstration and stakeholder involvement contribute to the development and deployment of the technology?

- Were the results of the demonstration provided for the adoption/adaption of other users of the technology? 
- Did the demonstration further the business objectives of private sector partners?

\section{Contractor Criteria}

- $\quad$ Proven Track Record: As this is the most environmentally challenging demonstration for technologies and most difficult to conduct due to its location on an island in Hawaii. technologies and companies must show successful demonstrations or operations at other less demanding locations before being invited to Kaho'olawe.

- Available Resources: The contractor must have sufficient resources to deploy the technology demonstration to Kaho'olawe. Onsite support cost support will be determined based on the Appropriations Act language.

\subsection{Castle Air Force Base, CA}

Castle Air Force Base is a base closure (BRAC II) site. The Base is a National Priority List site and is in the final phase of a CERCLA remedial investigation. The open burn/open detonation area located on the Base may contain unexploded ordnance. Requirements include the investigation for unexploded ordnance and media contaminated with explosive compounds. The safety plan for remedial action has recently been approved.

\subsubsection{Purpose/Goals of Demonstration}

To demonstrate innovative technologies that will improve (better, faster, safer, or cheaper) the remediation of open burn/open detonation areas. The proposed demonstrations and DOIT Committee involvement are narrow in scope as the cleanup process is fairly advanced.

\subsubsection{Description of Project}

The open burn/open detonation area may contain unexploded ordnance and media contaminated with explosive compounds. Surface and subsurface detection is required. Small arms munitions are considered the primary type of unexploded ordnance that may be found. Instrumentation currently in use cannot detect unexploded ordnance with 100 percent accuracy. Improved detection ability for unexploded ordnance is needed as well as improved methods to analyze media in a cost effective manner. Stakeholder participation methodology will be demonstrated.

\subsubsection{Organization/Management}

The DOIT Committee demonstration will work with the current cleanup efforts of the site manager and the base reuse committee, the Castle Joint Powers Authority. Suggestions of additional stakeholders will be made, if appropriate, and opportunities to demonstrate new technologies will be encouraged. 


\subsubsection{Timing/Schedule of Activities}

Working relationships need to be established as soon as possible.

\subsubsection{Estimated Costs/Funding Status}

Funding would be provided through the base closure fund.

\subsubsection{Selection Criteria}

\section{Site Criteria}

- Jurisdiction: Department of the Air Force

- Current and Future Land Use: Castle Air Force Base began operation in 1941 as a flight training, aircraft maintenance, and fire training facility. The April 1993 Draft Final Remedial Investigation Workplan identified approximately 121 areas to be investigated for contaminatios, including the 85-acre open burn/open detonation area.

The local reuse committee has identified various options for Base reuse. The Air Force plans to release the Castle Air Force Base Record of Decision for closure in January 1994. This Record of Decision will describe how the property will be conveyed.

- Potential Risk: There is potential risk from unexploded ordnance and contaminated media from residual contaminants in the open burn/open detonation area from demilitarization of munitions.

- Representative Site: This site is typical of an Air Force installation where small arms munitions are the primary ordnance items being destroyed.

- Current Public Awareness and Involvement: Local citizens, businesses, and government are considered the principal stakeholders and have had involvement through the Base reuse committee.

- Economic Benefit to Society from Remediation of the Site: Maximum reuse of the Base lands and facilities is important to ameliorate the negative economic effect of Base closure.

- Site Conditions:

- Range of Contaminant Values: A small variety of munitions types that is primarily concentrated within a few small areas.

- Contamination Characteristics: Primarily small arms unexploded ordnance and contaminated media from residual chemicals after open burn/open detcnation. 
- Site-to-site Variables: High concentrations in open burn/open detonation pits with the possibility of ejecta throughout the remainder of the 85 acres.

- Environmental Variables: The site is small enough to be essentially uniform. It is located in Central California in the San Joaquin Valley.

- Access: Excellent.

- Infrastructure: The Castle Air Force Base infrastructure is adequate to support demonstrations.

- Isolated Location: Castle Air Force Base is located in central California, adjacent to Atwater. California (population 22,585). Surrounding communities include Winton (population 7,583), Livingston (population 7,103), and Merced, (population 58,000), which is approximately 8 miles south.

\section{Technology Criteria}

Is the technology better, faster, safer, cheaper for cleanup in this environment?

- Test Date: To be determined.

- Potential for Timely Commercialization: Proven technologies of the type to be demonstrated here are in demand for other base closures in the United States and around the world.

- Support for Technology: Do the Stakeholders support use of the technology to be demonstrated?

- Part of a Technology "Test-off or Competition:" This is not part of a test-off or competition.

- Regulatory Process Issues: To be determined.

- Quality Assurance/Quality Controls: To be determined by the site manager and local stakeholders.

- Measurable Outcomes: To be determined by the site manager and local stakeholders.

\section{Evaluation Criteria}

- Technical

- Were test objectives achieved?

- Did the demonstration add to the understanding of capabilities of the tested technology?

- Were the demonstration protocols adequate?

- Did the demonstration advance the state of the technology? 
- Are the results from the demonstration applicable to other sites?

- Process

- Was there appropriate stakeholder involvement?

- Were stakeholder concerns adequately addressed?

- Did the demonstration contribute to commercialization of the technology?

- Did the demonstration and stakeholder involvement contribute to the development and deployment of the technology?

- Were the results of the demonstration provided for the adoption/adaption of other users of the technology?

- Did the demonstration further the business objectives of private sector partners?

Contractor Criteria

Criteria to be determined by the site manager and stakeholders.

\subsection{Sierra Army Depot, California}

The Sierra Army Depot, located at Herlong, California, approximately 50 miles north of Reno, Nevada, is currently the site of a number of technology demonstrations. It is a major munitions demilitarization site. Both the States of California and Nevada are concerned with the environmental effects of the demilitarization process, including air and ground-water contamination. The DOIT Committee should work with the Department of the Army to make this a major test facility for a wide range of ordnance explosive waste issues.

\subsubsection{Purpose/Goals of Demonstration}

To demonstrate the stakeholder methodology in support of developing innovative technologies for the demilitarization of ordnance and the remediation of surface, subsurface, and underwater unexploded ordnance and media contamination.

\subsubsection{Description of Project}

Initially focus on contaminated media demonstration projects, followed by innovative methods for demilitarization of munitions, and then underwater detection and remediation of unexploded ordnance. This would be a research and development and applied technology effort to clean up problems at the installation, but it would also provide a test bed for technologies that would be appropriate to a wide variety of installations. 


\subsubsection{Organization/Management}

The research and development program would be managed by the Army Environmental Center. The site manager would work with a local stakeholders group to gauge support for the technologies and environmental concerns that need to be remediated.

\subsubsection{Timing/Schedule of Activities}

Activities are currently underway. The DOIT Committee would work with the Army Environmental Center and the site manager to bring additional technology demonstrations to the installation.

\subsubsection{Estimated Costs/Funding Status}

The Strategic Environmental Research and Development Program would be the primary source of funding. Additional funds might be available from Defense Environmental Restoration Program appropriations. Costs would be determined on an individual demonstration basis.

\subsubsection{Selection Criteria}

Site Criteria

- Jurisdiction: Department of the Army.

- Current and Future Land Use: The War Department acquired the initial lands in 1932. The State of California transferred Honey Lake to the War Department during World War II, with an additional 1,800 acres transferred from the Department of the Interior in 1958 for the open burn/open detonation area. Honey Lake was used as a bombing range during World War II. In 1976, the Department of Defeinse attempted to return Honey Lake to the State of California, but the State would not accept it until it could be certified as clean. The installation is currently, and will continue to be, used for the demilitarization of obsolete munitions.

- Potential Risk: Risk from ground-water contamination is potentially a major problem. 'The contamination plume from the open burn/open detonation area has moved 2,200 feet in the last 5 years toward the Depot. Additionally, the Carson Water District wants to pump water from the Bedell Flats area 6 to 10 miles east of the Depot. This pumping may accelerate the spread of the plume.

- Representative Site: This site has many problems that can be found at other sites, but the problems are magnified by the large quantities of munitions demilitarized at this location. 
- Current Public Awareness and Involvement: There is public concern about environmental impacts from operations at the Depot. The organization of a stakeholders group would be a major DOIT Committee contribution to the environmental efforts being made by the Army at the Depot.

- Economic Benefit to Society from Remediation of the Site: Remediation of the contaminants in the ground water would lessen the probability of problems with municipal water development planned for the area. Improved demilitarization processes would lessen the likelihood for contaminants to enter the environment and be transported off the installation. Establishing the Depot as a major test facility would aid the local economy.

- Site Conditions:

- Range of Contaminant Values: A wide variety of ordnance and explosives waste.

- Contamination Characteristics: Contamination includes soil and air media, unexploded ordnance and munitions waste in the surface, subsurface, and underwater.

- Site-to-Site Variables: The primary variable is the presence of unexploded ordnance in Honey Lake and on the land.

- Environmental Variables: The Depot is located at an elevation of 4,500 to 5,500 feet on a south facing bajada of the Skedaddle Mountains.

- Access: Good access on highways and Depot roads.

- Infrastructure: The Depot's existing infrastructure should accommodate most requirements for demonstrations.

- Isolated Location: The location is sparsely populated; the Depot is the major population center in the area.

\section{Technology Criteria}

Is the technology better, faster, safer, cheaper for cleanup in this environment?

- Test Date: Tests are already underway.

- Potential for Timely Commercialization: The technologies to be tested/demonstrated are in demand at many active military instillations and instillations identified for base closure. The technologies are in demand worldwide. 
- Support for Technology: The States of Nevada and California and the local citizenry are concerned with the environmental cleanup of the Depot.

- Part of a Technology "Test-off or Competition:" This is not part of a test-off or competition.

- Regulatory Process Issues: To be determined.

- Quality Assurance/Quality Controls: To be determined by the site manager and local stakeholders.

- Measurable Outcomes: To be determined by the site manager and local stakeholders.

\section{Evaluation Criteria}

- Technical

- Were test objectives achieved?

- Did the demonstration add to the understanding of capabilities of tested technology?

- Were the demonstration protocols adequate?

- Did the demonstration advance the state of the technology?

- Are the results from the demonstration applicable to other sites?

- Process

- Was there appropriate stakeholder involvement?

- Were stakeholder concerns adequately addressed?

- Did the demonstration contribute to commercialization of the technology?

- Did the demonstration and stakeholder involvement contribute to the development and deployment of the technology?

- Were the results of the demonstration provided for adoption/adaption of other users of the technology?

- Did the demonstration further the business objectives of private sector partners?

\section{Contractor Criteria}

Criteria to be determined by the site manager and stakeholders. 


\subsection{Black Hills Ordnance Depot, South Dakota}

The U.S. Army Corps of Engineers, Huntsville Division, currently has an applied technology demonstration effort underway at the Black Hills Ordnance Depot. The DOIT Committee could form a partnership with the Corps of Engineers as part of an effort to develop stakeholder involvement and risk assessment methodology for remediation of formerly used Defense sites.

\subsubsection{Purpose/Goals of Demonstration}

A partnership with the Corps of Engineers for use of stakeholders in applied technology demonstrations.

\subsubsection{Description of Project}

The Corps of Engineers is testing existing aerial remote sensing technology to meet its remediation requirements for formerly used Defense sites. Black Hills is a Corps of Engineers remediation site.

\subsubsection{Organization/Management}

Demonstrations would be managed by the Huntsville Division of the Corps of Engineers as technical ordnance manager, and the Omaha (geographical) District as the lead project manager.

\subsubsection{Timing/Schedule of Activities}

The demonstration of aerial remote sensing is scheduled to be completed by the first quarter of FY 1994. Other demonstrations will be scheduled as appropriate. A new Broad A.gency Announcement is being prepared for additional demonstrations.

\subsubsection{Estimated Costs/Funding Status}

Funding would be from the formerly used Defense sites cleanup appropriations.

\subsubsection{Selection Criteria}

Site Criteria

- Jurisdiction: Department of the Army

- Current and Future Land Use: Private ownership used for cattle grazing and hunting.

- Potential Risk: Primary risk is from unexploded ordnance in the open burn/open detonation area and any burial sites that may be on the installation.

- Representative Site: This site is representative of unexploded ordnance problems at a number of installations in the Western United States. 
- $\quad$ Current Public Awareness and Involvement: The public is informed of the CERCLA process for ordnance remediation. The public realizes that site investigations will be carried out in FY 1994.

- Economic Benefit to Society from Remediation of the Site: Economic benefits will be evaluated during the study phases. They will accrue from risk reduction associated with land use.

- Site Conditions:

- Range of Contaminant Values: Potential for small arms, conventional ammunition, bombs, grenades, mines, rockets, ammunition components, bulk explosives, and chemical agents.

- Contamination Characteristics: Disposal sites are eroding and ordnance constituents are becoming exposed.

- Site-to-Site Variables: Open burn/open detonation areas with widespread ordnance and explosives waste scrap and possible unexploded ordnance, also dump sites for ordnance explosive waste scrap within the open burn/open detonation area. Possibility of chemical warfare material buried in trenches or pits.

- Environmental Variables: Weather and foliage effect sensors.

- Access: Paved roads within the former Army depot. Dirt roads to the open burn/open detonation grounds.

- Infrastructure: None.

- Isolated Location: No. Private property.

Technology Criteria

- Is the Technology Better, Faster, Safer, Cheaper for Cleanup in this Environment? Yes, for current demonstration.

- Test Date: Completion of current demonstration by 1 st quarter FY 1994.

- Potential for Timely Commercialization: Possibly.

- Support for Technology: Yes, though truth testing on the ground is still required.

- Part of a Technology "Test-off or Competition:" This is not part of a test-off or competition.

- Regulatory Process Issues: None.

- Quality Assurance/Quality Controls: To be determined by the site managers. 
- Measurable Outcomes: To be determined by Corps of Engineers, Huntsville Division, and the site manager.

Evaluation Criteria

- Technical

- Were test objectives achieved?

- Did the demonstration add to the understanding of capabilities of the tested technology?

- Were the demonstration protocols adequate?

- Did the demonstration advance the state of the technology?

- Are the results from the demonstration applicable to other sites?

- Process

- Was there appropriate stakeholder involvement?

- Were stakeholder concerns adequately addressed?

- Did the demonstration contribute to commercialization of the technology?

- Did the demonstration and stakeholder involvement contribute to the development and deployment of the technology?

- Were the results of the demonstration provided for the adoption/adaption of other users of the technology?

- Did the demonstration further the business objectives of private sector partners?

Contractor Criteria

Criteria to be determined by the site manager and stakeholders.

\subsection{Sunflower Army Ammunition Plant, Lawrence, Kansas}

This plant is typical of a number of munitions manufacturing plants that have contaminated water and soils on the property. Additionally, the plant has been identified as a candidate for a national large rocket motor demilitarization facility.

\subsubsection{Purpose/Goals of Demonstration}

To develop a national test site for contaminated media for research and development of advanced technologies and to remediate contaminated media at the site. 


\subsubsection{Description of Project}

Innovative technologies to be demonstrated: Decontamination of waters containing nitrates, guanidine nitrate (guanidinium ion), ammonia, and sulfates. Presently, evaporative lagoons are used to hold waters that have previously been treated by alkaline hydrolysis to break down nitroguanidine; use of the lagoons is a short-term measure at best.

\subsubsection{Organization/Management}

To be determined between Army Environmental Center; Army Armament, Munitions, and Chemical Command; and the Corps of Engineers.

\subsubsection{Timing/Schedule of Activities}

Many studies and activities have taken place since the 1970's. The establishment of a national test facility is yet to be approved.

\subsubsection{Estimated Costs/Funding Status}

Funding would be provided through the Defense Environmental Restoration Program and the Strategic Environmental Research and

Development Program.

\subsubsection{Selection Criteria}

Site Criteria

- Jurisdiction: Department of the Army

- Current and Future Land Use: The installation contains 9,065 acres plus 479 acres of easements. The Sunflower Army Ammunition Plant is a government-owned, contractor-operated, military industrial installation assigned to the jurisdiction of the Commanding General, Headquarters, U.S. Army Armament, Munitions and Chemical Command. The principal mission of the Sunflower Army Ammunition Plant is the mass production of solvent and solventless multi-base propellants. After the termination of production in mid-1971, the plant was placed in a standby status. In the period since standby began, other activities at Sunflower Army Ammunition Plant consisted of a major modernization program and the reactivation of a portion of the plant for the production of nitroguanidine.

- Potential Risk: There are a number of sites where ground water, surface water, and soil are contaminated with heavy metals, acid, chlorinated solvents, and ordnance compounds.

- Representative Site: This site is representative of this type munitions manufacturing plant in the United States and other countries. 
- $\quad$ Current Public Awareness and Involvement: Surrounding residents, employees at the Sunflower Army Ammunition Plant, and State and Federal environmental regulators are aware of and sensitive to the issues at the plant. (It is unknown if there is a stakeholders group already formed.)

- Economic Benefit to Society from Remediation of the Site: Remediation at the site would reduce the likelihood of offsite contaminants affecting the health of humans, livestock, and farm products. The establishment of a test facility for research and development on the plant site would add employment opportunities in the local area. Remediation of similar sites in the United States and other countries would potentially make these sites available for other uses.

- Site Conditions:

- Range of Contaminant Values: There is a variety of chemical contaminants associated with the manufacturing process.

- Contamination Characteristics: Site characterization was completed by the U.S. Army Toxic and Hazardous Materials Agency in the 1980's. Fifty potentially contaminated sites were identified with heavy metals, acid, ordnance compounds, chlorinated solvents or other compounds, or a combination of these.

- Site-to-Site Variables: The site variables relate to the types of contamination.

- Environmental Variables: These are the contaminated media of surface water, ground water, or soil.

- Access: Good.

- Infrastructure: The infrastructure includes facilities at the Sunflower Army Ammunition Plant and in Lawrence (12 miles) and Kansas City (25 miles). The Plant has an existing hazards sensitivity testing lab and basic environmental analysis capability; a sequential batch, biotreatment waste water treatment plant focused on the treatment of nitrate-contaminated waste water; and igloos and magazines that are empty and available for use.

- Isolated Location: Sunflower Army Ammunition Plant is a small installation that is no longer isolated by distance from encroaching suburbs.

\section{Technology Criteria}

Is the Technology Better, Faster, Safer, Cheaper for Cleanup in this Environment? 
- Test Date: Tests and cleanup measures are already underway. The date of recognition as a "national test bed site" is yet to be determined.

- Potential for Timely Commercialization: The technologies to be tested/demonstrated are in demand at other United States facilities and similiar facilities worldwide.

- $\quad$ Support for the Technology: Yes.

- Part of a Technology "Test-off or Competition:" This is not part of a test-off or competition.

- Regulatory Process Issues: To be determined.

- Quality Assurance/Quality Controls: To be determined by the site manager and local stakeholders.

- Measurable Outcomes: To be determined by the site manager and local stakeholders.

Evaluation Criteria

- Technical

- Were test objectives achieved?

- Did the demonstration add to the understanding of capabilities of the tested technology?

- Were the demonstration protocols adequate?

- Did the demonstration advance the state of the technology?

- Are the results from the demonstration applicable to other sites?

- Process

- Was there appropriate stakeholder involvement?

- Were stakeholder concerns adequately addressed?

- Did the demonstration contribute to commercialization of the technology?

- Did the demonstration and stakeholder involvement contribute to the development and deployment of the technology?

- Were the results of the demonstration provided for the adoption/adaption of other users of the technology?

- Did the demonstration further the business objectives of private sector partners?

\section{Contractor Criteria}

Criteria to be determined by the site manager and stakeholders. 


\subsection{Delta Range, Alaska, and Davis Range, Colorado}

These two formerly used Defense site range areas were identified in the report of the May 14 and 15, 1993, Military Munitions Waste Work Group meeting. These sites have been deleted from the first round of demonstration sites as being too limited in scope and possessing a low risk to the general public.

These formerly used Defense sites will be remediated by the Corps of Engineers based on the planned end use of the lands as determined by the managing agencies and input from other stakeholders. 


\section{APPENDICES}


Appendix A - National Department of Defense Environmental Technology Sites Program for Energetics under the Strategic Environmental Research and Development Program 


\section{TITLE: NATIONAL DOD ENVIRONMENTAL TECHNOLOGY SITES PROGRAM FOR ENERGETICS}

\section{Project Description:}

Technical Objective: The technical objective of this program is to provide specific sites where emerging energetic contamination treatment technologies developed by DoD, DOE, EPA, and both public and private sectors can be comparatively demonstrated, and evaluated.

Technical Approach: The proposed approach will include:

1) Evaluate potential sites for inclusion in program. Key site selection criteria could include, but not be limited to: a) wide representative range of soil and groundwater energetics contamination; b) soil should range from sandy to thick clay, hydrogeological environment should at a minimum include a $40 \mathrm{ft}$ permeable aquifer with impermeable bed rock formations; c) readily accessible from a major transportation hub; d) site support available with accessible utilities and assistance from the Director of Engineering and Housing (DEH) or comparable Office/District; e) site expansion capabilities to include laboratory and personnel support facilities.

2) Establish a technology selection/work group. The problem area work groups will consist of members from both the user and developer communities. Members primary responsibility will be to recommend technology selection criteria. Technology selection criteria would include, but not be limited to: a) emerging technologies developed from SERDP participants, as well as, those of other government agencies and the private sector; b) technologies which address current contamination problems; c) technologies which exhibit potential cost savings over currently used technology; d) technologies which have the potential to meet established clean up levels.

3) Establish regulatory and safety requirements.

4) Examine physical, chemical, and biological limitations through site characterization analysis.

5) Evaluate natural attenuation of existing contamination.

6) Review technology-contamination suitability and provide technology selection/fabrication/installation guidelines.

\section{Funding by Task:}

See attached funding table.

\section{Performers:}

In addition to DoD, DOE, and EPA, other principal partners in this initiative will be other federal agencies and services, as well as, both public and private sectors. The SERDP Executive Director will provide program oversight, and USATHAMA will provide program management. The technology selection and oversight board will consist of members from both the user and developer communities. On site execution and day to day oversight will be performed by private firm contractors and/or other government agencies. 


\section{Technical Point of Contact:}

Mr. Robert Bartell/Ms. Julia Kilduff USATHAMA

Research \& Technology Dev. Br.

Aberdeen Proving Ground, MD 21010-5401

(410) 671-2054 
Military Munitions Waste Working Group

Appendix B - Working Group List

67 
Military Munitions Waste Working Group as of January 5, 1994

Charles Appleby

SCITOR Corporation

2411 Dulles Corner Road

Sulte 440

Herndon, VA 22071

(703) 713-1800

FAX (703) 713-1801

Jim Austreng*

Department of Toxic Substances Control

10151 Croydon Way \#3

Sacremento, CA 95827-2106

(916) 255-3702

FAX (916) 255-3697

John Beckum

Environmental Systems \& Services Incorporated 100 Valley Road

Suite 103

Mi. Arlington, NJ 07856

(201) 770-4422

FAX (201) 770-4574

John Boyden

President,

UXB International Incorporated

14800 Conference Drive

Suite 100

Chantilly, VA 22021

(703) 803-8904

FAX (703) 803-9355

Grace Bukowski

Citizen Alert

P.O. Box 5339

Reno, NV 89513

(702) $827-4200$

FAX (702) 827-4299

Kendall Casey

Ballena Systems Corporation

5820 Stoneridge Mall Road

Suite 205

Pleasanton, CA 94588

(510) 460-3740

FAX (510) 460-3751

\author{
Pam Clements \\ Commander, \\ Indian Head Division Navy Ordnance Environmental \\ Support Office \\ Code OE \\ Indian Head, MD 20640-5035 \\ (301) 743-4534 \\ FAX (301) 743-6749 \\ Dr. Ron Crawford \\ Co-Director. \\ Center for Hazardous Waste \\ University of Idaho \\ Moscow, Idaho 83844 \\ (208) 885-6580 \\ FAX (208) 885-5741 \\ Jim Cummings \\ Technology Innovation Office OS110-W \\ Office of Solid Waste \& Emergency Responsc \\ USEPA 401 M Street, SW \\ Washington, D.C. 20460 \\ (703) 308-8976 \\ F^X (703) $308-8528$ or 8505
}

William H. Dana

Project Manager,

Department of Environmental Quality

811 SW Sixth Avenue

Portland, OR 97204

(503) 229-6530

FAX (503) 229-5830

Jim Drake

DoD Explosive Safety Board

Hoffman Building \# 1

Suite 586

2461 Eisenhower Avenue

Alexandria, VA 22331-0600

(703) 325-089 I

FAX (703) $325 \cdot 6227$

Ray Duda

Utah Department of Environmental guality

Division of Solid \& Hazardous Waste

288 N. $1460 \mathrm{~W}$.

P.O. Box 144880

Salt Lake City, UT 84114-4880

(801) 538-6170

FAX (801) 538-6715

*Working Group Co-Spokesperson 
Larry E. Erickson

Director,

Great Plains-Rocky Mountain Department of Chemical Engineering

Kansas State University

Durland Hall

Manhattan, KS 66506-2502

(913) 532-4313

FAX (913) 532-7372

Grant Ferrier

Editor, Environmental Business

Publishing Incorporated

4454 Park Boulevard

Suite 306

San Diego, CA 92116

(619) 295-7685

FAX (619) 295-5743

Dick C. Green

EG\&G Idaho

P.O. Box 1624

Mail Stop 4129

Idaho Falls, ID 83415

(208) 526-2702

FAX (208) 526-5474

Dwight L. Hempel*

Bureau of Land Management

1849 C Street, NW (1000 LS)

Washington, DC 20240

(202) 452-7778

FAX (202) 452-7708

Barbara Hodischek

Program Manager.

Hazardous Radioactive Materials Bureau

525 Camio De Los Marquez

P.O. Box 26110

Sante. Fe, NM 87502

(505) 827-4308

FAX (505) 827-4361

Andrew E. Hooper

Chief, Advanced Technology Office

STEYP-TD-ATO

U.S. Army Yuma Proving Ground

Yuma, AZ 85365

(602) 328-6111

FAX (602) 328-6283
Thomas O. Hunter, Ph.D.

Sandia National Laboratories

1515 Eubank, SE

Org. 6900, Building \#823

Room 4042

Albuquerque, NM 87123

(505) 844-3763

FAX (505) 844-7437

Jerold L. Johnson

U.S. Bureau of Mines - DOI

Salt Lake City Research Center

Mail Stop 6260

729 Arapeen Drive

Salt Lake City, UT 84108-1283

(801) 584-4157

FAX (801) 584-4134

Les Keffer

HQ USAF/CEVV

Building \#516

Bolling AFB

Washington, DC 20332-5000

(703) 697-3341

FAX (703) 695-8943

Dr. Teri Knight

The Nature Conservancy

4220 S. Maryland Parkway

Suite 222

Las Vegas, NV 89119

(702) 737-8744

FAX (702) 737-5787

Eric Koglin

USEPA-ODT

944 East Harmon

Las Vegas, NV 89119

(702) 798-2432

FAX (702) 798-2637

Dave Minedew

Bureau of Federal Facilities

Nevada Division of Environmental Protection

$333 \mathrm{~W}$. Nye Lane

Carson City, NV 89710

(702) 687-5872 ext. 3027

FAX (702) 885-0868

*Working Ciroup Co-Spokesperson 
Gary Olhoeft

U.S. Geological Survey

1527 Cole Boulevard

Room 359

Golden, CO 80401

(303) 236-1212

FAX (303) 236-1425

Kelly Rigano

Program Manager for Unexploded Ordnance Detec-

tion \& Remediation Program

U.S. Army Environmental Center

ATTN: SFIM-AEC-TCC (Rigano)

Aberdeen Proving Ground, MD 21010-5401

(410) 671-1557

FAX (4.10) 671-1680

Verne Rosse

Nevada Division of Environmental Protection

$123 \mathrm{~W}$. Nye Lane

Room 108

Carson City, NV 89710

(702) $687-5872$ ext. 3045

FAX (702) 885-0868

Dave Shelton

Chief,

Hazardous Waste Control Section

Hazardous Materials \& Waste Management Division

Colorado Department of Health

4300 S. Cherry Creek Drive

Denver, CO 80222-1530

(303) 692-3313

FAX (303) 759-5355

Jim Speer, Jr., Ph.D., JD

OVER-C

P.O. Box 396

Silverdale, WA 98383

(206) 692-7042

FAX (206) 792-0619

Merv Tano

Council of Energy Resources

1999 Broadway

Suite 2600

Denver, CO 80202

(303) 297-2378

FAX (303) 296-5690

Ross Vincent

Sierra Club

Box 4375

Pueblo, CO 81003

(719) 561-3117

FAX (719) 561 - 1149 (then hit 11)
Rob Wilcox

U.S. Army Corps of Engineers

Huntsville Division

Mandatory Center of Expertise

Explosive Ordnance Engineering

106 Wynn Drive

Huntsville, AL 35807

(205) 955-5802

FAX (205) 955-5788

Marvin F. Young

Aerojet

P.O. Box 3530

Rancho Cordova, CA 95741-3530

(916) 355-2064

FAX (916) 351-8660

\section{Alternates}

Gary Baughman (alternate to D. Shelton)

Hazardous Waste Control Section

Hazardous Materials \& Waste Management Division

Colorado Department of Health

4300 S. Cherry Creek Drive

Denver, CO 80222-1530

(303) 692-3313

FAX (303) 759-5355

Gene Clark

(in attendance for J. Drake Sept. 30, 1993)

DoD Explosives Safety Board

Hoffman Building \# 1

Suite 586

2461 Eisenhower Avenue

Alexandria, VA 22331-0600

(703) 325-0891

FAX (703) 325-6627

Jim Coppola (alternate to Rob Wilcox)

Program Manager for Ordnance \& Explosives/Wastes on Formerly Used Defense Sites

HQ. USACE

ATTN: CEMP-RF (Coppola)

20 Massachusetts Avenue. NW

Washington, DC 20314-1000

(202) 504-4992

FAX (202) 504-5011

James T. Firkins

(in attendance for B. Hodischek Sept 30, 1993)

New Mexico EMNRD

2040 South Pacheco

Santa Fe, NM 87505

(505) 827-5950

FAX (505) 438-3855 
Dan LaFleur (alternate to Clements)

Naval Surface Warfare Center

Indian Head Division

Navy Ordnance Environmental Support Office

Code OE 1

Indlan Head, MD 20640-5035

(301) 743-4534

FAX (301) 743-6749

Dave Larsen (alternate to Duda)

Utah Department of Environmental Quality

Division of Solid/Hazardous Waste

288 N. $1460 \mathrm{~W}$.

P.O. Box 144880

Salt Lake City, UT $84114-4880$

(801) 538-6170

FAX (801) 538-6715

William Maurits (alternate to Jim Drake)

DoD Explosive Safety Board

Hoffman Building \# 1

Suite 586

2461 Eisenhower Avenue

Alexandria, VA 22331-0600

(703) 325-0891

FAX (703) 325-6227

Sam Meacham (alternate to Tom Hunter)

Director,

Robotics \& Process Systems Division

Oak Ridge National Laboratory

P.O. Box 2008, 7601-6035

Oak Ridge, TN 37831-6305

(615) 574-7065

FAX (615) 574-4624

Dr. Clem Meyer (alternate to L. Keffer)

HQ UACE

CERO-M

Room 208

20 Massachusetts Avenue, NW

Washington, DC 20314

(202) 272-1850

FAX (202) 272-0907

Doug Nation (alternate to A. Hooper)

Office of the Under Secretary of Defense

Room 3E 1060

Pentagon

Washington, DC 20310-0103

(703) 695-7171

FAX (703) 693-7030
Dennis Samuelson (alternate to Dwight Hempel)

Nevada State Office (NV-940)

Bureau of Land Management

P.O. Box 12000

Reno, NV 89520-0006

(702) 785-6619

FAX (702) 785-6411

Carl Stubbs (alternate to B. Hodischek)

HRMB

525 Camino De Los Marquez

P.O. Box 26110

Sante Fe, NM 87502

(505) 827-4308

FAX (505) 827-4361.

\section{Observers and Advisors}

Julia Kilduff

U.S. Army Environmental Center

Research \& Technology

Aberdeen Proving Ground, MD 21010

(410) 671-2054

Richard $\mathrm{H}$. Beers

GEO-CENTERS Incorporated

10903 Indian Head Highway

Fort Washington, MD 20744

(301) 292-1010

FAX (301) 292-8717

Ann Blakeley

Earth Resources Corporalion

1227 Marshall Farms Road

Ocoee, Fl 34761

(407) 877-0877

FAX (407) 877-3622

Ray Conners

Earthfax Engineering

7324 South Union Park Avenue

Suite 100

Salt Lake City, UT 84047

(801) 561-1555

FAX (801) 561-1861

Spencer Eason

EBASCO Constructors Incorprated

1892 McFarland Avenue

Rossville, GA 30741

(706) 866-8990

FAX (706) 861-2531 


\author{
John E. Foley \\ GEO-CENTERS Incorporated \\ 7 Wells Avenue \\ Newton Centre, MA 02159 \\ (617) 964-7070 \\ (617) 527-7592
}

\section{Matt Kaye}

EOD Technology

111 Robertsville Road

Oak Ridge, TN 37830

(615) 483-0007

FAX (615) 481-0653

Eugene W. Langley

Global Environmental Solutions Incorporated/

Hercules

5000 S. $8400 \mathrm{~W}$.

Annex \# 1

Magna, UT 84044

(801) 251-5418

FAX (801) 251-2027

Elizabeth K. Lavach

Gadsby \& Hannah

1747 Pennsylvania Avenue, NW

Washington, DC 20006

(202) 429-9600

FAX (202) 429-9894

John Leininger

IT Corporation

5600 South Quebec

Englewood, CO 80111

(303) 793-5200

FAX (303) 793-5222

Peter O' Connor

Solarchem Environmental Systems Incorporated 7320 Smoke Ranch Road

Suite $\mathrm{H}$

Las Vegas, NV 89128

(702) 255-7055

FAX (702) 255-7280

Ed Roberson

GES/Hercules

5000 S. $8400 \mathrm{~W}$.

Annex \# 1

Magna, UT 84044

(801) 251-3680

FAX (801) 251-2027
Jerry Snyder

Naval EOD Technology Center

2008 Stump Neck Road

Indian Head, MD 20640-5070

(301) 743-6855

FAX (301) 743-6947

Larry Tarno

Denver Research Institute

2050 East Iliff Avenue

Denver, CO 80208

(303) 871-4377

FAX (303) 871-2716

\section{Staff}

Cheryl Dobbins

(faci"itator)

Basic .echnologies International

4641 Montgomery Avenue

Bethesda, Md 20814

(301) 907-0322

$\operatorname{FAX}(301) 654-5231$

Chris Mckinnon

Jim letrr

Western Governors' Association

60017 th Street

Suite $1705 \mathrm{~S}$.

Denver, CO 80202

(303) 623-9378

(303) 534-7309

Steve Loucks

Coleman Research Corporation 925 L'Enfant Center, SW

8th Floor

Washington, DC 20024

(202) 863-0916

FAX (202) 863-9529
Please note that the findings of the Military Munitions Waste Working Group Report do not necessarily reflect the views of every member of the working group. Some members were not able to participate in the develomment of the report, nor were they able to fully revieu' its contents. This report does not represent the official view of any federal agency or department, state. or other group. 

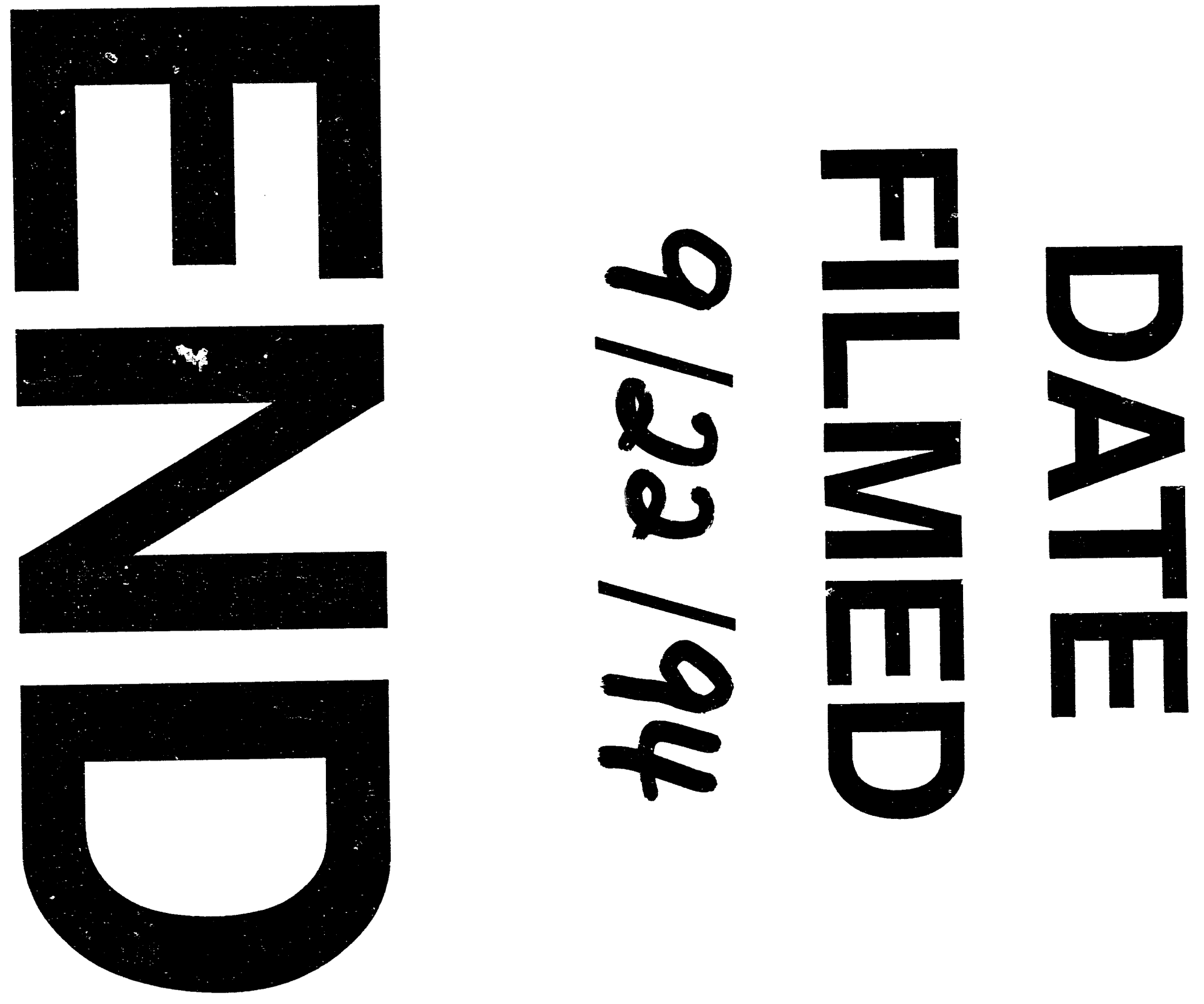
